AperTO - Archivio Istituzionale Open Access dell'Università di Torino

\title{
Chapter 39 Ecology and Evolution of Fungal-Bacterial Interactions
}

\section{This is the author's manuscript}

Original Citation:

\section{Availability:}

This version is available http://hdl.handle.net/2318/1634115

since 2017-05-15T14:22:26Z

Publisher:

CRC Press Taylor \& Francis Group

Published version:

DOI:10.1201/9781315119496-40

Terms of use:

Open Access

Anyone can freely access the full text of works made available as "Open Access". Works made available under a Creative Commons license can be used according to the terms and conditions of said license. Use of all other works requires consent of the right holder (author or publisher) if not exempted from copyright protection by the applicable law. 
This is the author's final version of the contribution published as:

Olsson, Stefan; Bonfante, Paola; Pawlowska, Teresa E.. Chapter 39 Ecology and Evolution of Fungal-Bacterial Interactions. CRC Press Taylor \& Francis Group. 2017. pp: 563-584.

in

The Fungal Community Its Organization and Role in the Ecosystem,Fourth Edition

The publisher's version is available at:

http://www.crcnetbase.com/doi/pdf/10.1201/9781315119496-40

When citing, please refer to the published version.

Link to this full text:

http://hdl.handle.net/ 


\section{Ecology and Evolution of Fungal-Bacterial Interactions}

2 Stefan Olsson $^{1}$, Paola Bonfante ${ }^{2}$ and Teresa E. Pawlowska ${ }^{3}$

$3{ }^{1}$ Department of Plant \& Environmental Sciences, University of Copenhagen, Copenhagen,

4 Denmark, sto@plen.ku.dk; ${ }^{2}$ Department of Life Sciences \& Systems Biology, University of

5 Torino, Torino, Italy, paola.bonfante@unito.it; ${ }^{3}$ School of Integrative Plant Science, Plant

6 Pathology \& Plant-Microbe Biology, Cornell University, Ithaca, NY 14853-5904, USA,

7 tep8@cornell.edu.

I. General Introduction

11 II. Definitions and Concepts

12 III. Non-Heritable Symbiotic Interactions

A. Introduction

B. Candida albicans-Pseudomonas aeruginosa antagonism

C. Mycophagy and biological control of fungi by bacteria

D. Fungal predation and dependence on bacteria

E. Highways carrying hyphae-associated bacteria

F. Mycorrhiza helper bacteria

G. Recognition and assembly of the non-heritable symbionts to form the fungal-bacterial metaorganism

21 IV. Vertical Transmission and the Evolution of Mutualisms

\section{V. Heritable Symbiotic Interactions}

A. Introduction 
B. Heritable facultative mutualisms

C. Heritable antagonisms

26 VI. Future Developments

A. Introduction

B. Novel tools to study fungal-bacterial metaorganisms

29

C. Physiological processes known from other host-symbiont systems

\section{VII. Closing Remarks}




\section{I. General Introduction}

33 The propensity of fungi to synthesize compounds active against bacteria (Broadbent 1966) and

34 the predilection of bacteria to produce antifungals (Kerr 1999) gave rise to a paradigm that

35 interactions between representatives of these two groups of organisms are of an antagonistic

36 nature. While, indeed, evidence for fungal-bacterial antagonisms is abundant (Espuny Tomas et

37 al. 1982; Leveau and Preston 2008; Susi et al. 2011; Palaniyandi et al. 2013; Pawlowska et al.

38 2012; Pliego et al. 2011), the recent accumulation of newly discovered associations in which

39 fungi cooperate with bacteria (Kobayashi and Crouch 2009; Frey-Klett et al. 2011) indicates that

40 such reciprocally beneficial interactions are more common than previously thought. As

41 functional and mechanistic aspects of many of these interdomain relationships were reviewed in

42 detail elsewhere (Grube and Berg 2009; Kobayashi and Crouch 2009; Peleg, Hogan, and

43 Mylonakis 2010; Frey-Klett et al. 2011; Martin and Schwab 2012; Scherlach, Graupner, and

44 Hertweck 2013), our discussion will focus on factors that contribute to their stability over

45 ecological and evolutionary time. We hope that, by directing attention to this important but

46 currently neglected aspect of fungal-bacterial interactions, we will inspire new directions of

47 research on the biology of these organisms.

\section{II. Definitions and Concepts}

50 We use the term symbiosis in the de Bary's sense of "the living together of unlike organisms",

51 without implications whether this relationship has positive or negative fitness consequences for

52 any of the interacting partners (Martin and Schwab 2012). Thus in terms of fitness outcomes, the

53 symbiosis can assume the forms of a mutualism $(+/+)$, commensalism $(+/ 0)$, and antagonism, 
including competition $(-/-)$, amensalism $(-/ 0)$, parasitism and predation/grazing $(-/+)($ Lewis

55 1985). We doubt that strictly neutral relationships (0/0) exist among the symbiotic partners.

56 We recognize that practically all biota on the planet are components of stabile assemblages of

57 organisms, referred to as metaorganisms (Bosch and McFall-Ngai 2011). Although not ideal,

58 this term is reasonably well defined and increasingly coming into use (Trinchieri 2014; Biagi et

59 al. 2012). We employ it in our discussions of entities formed in the process and as a

60 consequence of fungal-bacterial interactions (Fig. 1). Thus it is the metaorganism that survives

61 in nature and changes over time due to evolution of its individual constituents, their composition,

62 and the roles in the metaorganism. It is important to note that fungal-bacterial metaorganisms

63 may be, in turn, components of higher-level metaorganisms comprising also plant or animal

64 hosts. We refer to the fungal constituents of the fungal-bacterial metaorganism as the hosts and the bacterial partners as the symbionts. Both hosts and symbionts can be represented by a single

66 species, or they can each comprise a multi-species consortium in which different species interact

67 with each other. In terms of physical interface between the partners, bacterial symbionts can act

68 as endobionts/endosymbionts living intracellularly inside the hyphae, or as

69 ectobionts/epibionts/ectosymbionts/episymbionts associated with the surface of the hyphae or

70 in the close vicinity of the hyphae, often in biofilms consisting of several layers of bacteria held

71 together by a matrix. Metaorganism formation can take several routes. Most known associations

72 of fungi with bacteria are non-heritable, with bacterial symbionts assembled by each generation

73 of the host de-novo from the environment. In contrast, heritable bacterial symbionts are

74 transmitted vertically from the host parent to the next generation of the fungal-bacterial

75 metaorganism. Vertical transmission can be either strict/exclusive, or mixed, i.e. punctuated by

76 instances of horizontal transmission in which bacteria spread between host individuals of the 
same generation. Bacterial symbionts can be free-living. They can also be confined to their eukaryotic host's intracellular environment and have no extracellular state (obligate endobacteria), or capable of living both in fungal cells and in extracellular environments

80 (facultative endobacteria). Finally, mutualistic symbionts can be divided based on their effects on host survival into essential and nonessential. Because of varying levels of integration and complexity, understanding of fungalbacterial metaorganisms is at present in its infancy. We believe that many facets of this biological complexity can be studied and framed conceptually using the existing ecology and evolution tools and theory. For example, some spontaneously formed fungal-bacterial associations can be explained by ecological fitting, in which organisms establish novel relations with other species thanks to the traits that they already possess when they encounter their new partners (Janzen 1985). Such relationships often develop in man-made or disturbed environments. Other interactions are expected to be products of prolonged reciprocal selection that tie individual partner taxa or guilds of interacting partners into ecologically and evolutionarily stable alliances. One of the approaches for organizing the knowledge on how these entities are structured internally and coexist in ecosystems involves reconstruction of symbiotic networks to inventory and display interactions among taxa within and across different metaorganisms. In addition to being an inventory of taxa and their interactions, the networks are expected to offer insights into the coevolutionary processes that shape the diversity of both metaorganism constituents and metaorganisms themselves (Bascompte and Jordano 2013). In particular, they represent patterns of selection operating among genetically variable multi-species groups in which the species convergently adapt and specialize on a suite of symbiotic traits rather than directly on other species (Thompson 2005). While, historically, symbiotic networks 
have been used to represent interactions in mutualisms (Bascompte and Jordano 2013), they can

101 also accommodate interactions with negative fitness outcomes. Another framework that can help

102 explore and conceptualize fungal-bacterial interactions is the geographic mosaic of coevolution,

103 GMC, model (Thompson 2005). According to this model, partners interact across their

104 geographic ranges. In some locations, known as coevolutionary hot spots, they are subjected to

105 reciprocal selection. In others, known as coevolutionary cold spots, local selection is not

106 reciprocal. Several factors, including gene flow, genetic drift, mutations, migration, and local

107 extinctions, contribute to variation in the patterns of natural selection between the habitats.

108 These predictions can be readily translated into set of questions to guide investigations of fungal-

109 bacterial interactions (Gomulkiewicz et al. 2007).

110 While many fungal-bacterial interactions remain ambiguous in terms of fitness outcomes,

111 the vast majority of them are either undisputed antagonisms or mutualisms. The astounding

112 ubiquity and prevalence of antagonistic interactions present in all ecosystems is related to the

113 fact that living organisms represent excellent sources of energy and nutrients, which otherwise

114 are available in limiting quantities (Thompson 2014). In fact, even mutualisms are viewed as

115 reciprocal exploitations that nonetheless provide net benefits to each partner (Herre et al. 1999).

116 Moreover, despite their fundamental significance to the evolution and functioning of the

117 biosphere, the mechanisms that promote the initial establishment and evolutionary stability of

118 mutualisms are not fully explored. Like antagonisms, mutualisms can form instantaneously as a

119 consequence of ecological fitting (Janzen 1985; Hom and Murray 2014). They can be also

120 products of extensive reciprocal selection between the partners that initially interacted as either

121 antagonists or commensals (Aanen and Bisseling 2014). Conflicting interests of the interacting

122 partners, manifested by accepting benefits without reciprocating, make mutualisms vulnerable to 
123 failures. Yet, their evolutionary persistence suggests that certain mechanisms could ensure

124 mutualism stability (Trivers 1971). Several theoretical models have been proposed to explain

125 evolutionary stability of mutualisms. They include: (1) byproduct cooperation (Connor 1986;

126 Sachs et al. 2004), (2) the iterated prisoner's dilemma, IPD, model with the "tit-for-tat"

127 strategy (Axelrod and Hamilton 1981; Doebeli and Knowlton 1998; Sachs et al. 2004), (3)

128 partner-fidelity feedback, PFF (Bull and Rice 1991; Sachs et al. 2004; Weyl et al. 2010), (4)

129 partner choice (Bull and Rice 1991; Noë and Hammerstein 1994; Sachs et al. 2004), and (5)

130 compensatory evolution/addiction (Aanen and Hoekstra 2007). (1) Byproduct cooperation

131 involves interactions in which a focal partner receives a byproduct benefit from a donor and

132 natural selection shapes the focal partner to maximize these benefits by being cooperative toward

133 the donor (Connor 1986; Sachs et al. 2004). (2) The IPD model with the "tit-for-tat" strategy

134 applies to systems in which two partners, who engage in a series of interactions, are able to vary

135 their behavior in each interaction according to a partner's previous action (Axelrod and Hamilton

136 1981; Doebeli and Knowlton 1998; Sachs et al. 2004; Weyl et al. 2010). Cooperation is

137 maintained only when partners reciprocate in kind. Non-cooperative individuals are sanctioned

138 by their partners through termination of cooperation. (3) Like IPD, the PFF model applies to

139 systems in which two partners interact repeatedly. However, in PFF, fitness gains derived from

140 cooperation by one partner feed back to the other partner, thus the partner who fails to cooperate

141 harms its own fitness (Bull and Rice 1991; Sachs et al. 2004; Weyl et al. 2010). (4) Unlike IPD

142 and PFF, the partner choice model involves interactions of a focal individual with multiple

143 trading partners who are reciprocated based on the quality of goods and services offered, with the

144 most cooperative partner receiving the highest compensation (Sachs et al. 2004; Kiers et al.

145 2011). (5) The mechanism of compensatory evolution/addiction is expected to operate in 
mutualisms that evolved from antagonistic interactions, in host populations exposed initially to a

147 parasitic symbiont (Aanen and Hoekstra 2007). Under parasite pressure, host mutants are

148 favored that compensate for harmful effects of the parasite and thus suffer less damage. Once

149 such compensatory mutations are fixed, they may become deleterious to the host in the absence

150 of the parasite. As a consequence, a host population with such compensatory mutations will

151 become dependent on the presence of the parasite, leading ultimately to a conversion of an

152 antagonistic interaction into a stable mutualism.

153 For the sake of clarity, we divided our discussion of fungal-bacterial symbioses into

154 sections devoted to systems in which partners are assembled de novo in each generation versus

155 associations in which partners are transmitted together from generation to generation and

156 interactions are heritable. We also discussed the role of vertical transmission in evolution of

157 mutualisms from antagonisms. Finally, we suggested tools and future directions for studying

158 fungal-bacterial symbioses.

159

160 III. Non-Heritable Symbiotic Interactions

161 A. Introduction

162 All basic types of relationships, i.e. mutualisms, commensalisms, and antagonisms, can be found

163 among non-heritable fungal-bacterial symbioses. For some of them detailed knowledge is

164 available, others will be mentioned only briefly. Some bacteria associate directly with fungal

165 hyphae (Baschien et al. 2009; Cuong et al. 2011) and form biofilms on their surfaces (Simon et

166 al. 2015; Pion et al. 2013; Scheublin et al. 2010). These epibionts live in the hyphosphere, the

167 volume around hypha influenced by the hyphal presence (Errore. Riferimento a

168 collegamento ipertestuale non valido. . The bacterial symbionts can be antagonistic, as is

Eliminato: Staněk 1984 
169 typical for bacteria used for biocontrol of fungal pathogens (Mela et al. 2011; Cuong et al. 2011;

170 Jochum, Osborne, and Yuen 2006; Mathioni et al. 2013). They can also act as mutualists (Nazir,

171 Tazetdinova, and van Elsas 2014). However, it seems that there is a limited number of

172 fungiphilic bacterial taxa, i.e. taxa adapted to the mycosphere, that are involved in fungal-

173 bacterial symbioses (Lyons et al. 2005; Warmink, Nazir, and van Elsas 2009; Simon et al. 2015;

174 Baschien et al. 2009; Scheublin et al. 2010). Finally, some non-heritable interactions are quite

175 unexpected and thought provoking, like those formed by bacteria-farming fungi (Pion et al.

176 2013), or bacterivorous nematodes and nematophagous fungi (Wang et al. 2014; Hsueh et al.

177 2013).

178

179 B. Candida albicans-Pseudomonas aeruginosa antagonism

180 Because of their significance to human health, interactions between Candida albicans and

181 Pseudomonas aeruginosa attracted a lot of attention, which, in turn, yielded important insights

182 into the molecular mechanisms that underlie the coexistence of these two organisms in the

183 context of human disease (Peleg, Hogan, and Mylonakis 2010). C. albicans is a commensal

184 yeast found in the normal microbial flora of human oral, digestive, or vaginal mucosa (McManus

185 and Coleman 2014). It is acquired at birth or during physical contact. Factors affecting the

186 mucosal microbiome, such as the use of antibiotics, hormonal imbalance, or diet, can induce

187 non-life threatening C. albicans infections of mucosal surfaces, candidiasis (Scully, el-Kabir, and

188 Samaranayake 1994). In severely ill and immunocompromised individuals, C. albicans can

189 spread into the blood stream causing invasive and often fatal candidaemia (Eggimann, Garbino,

190 and Pittet 2003). C. albicans invasions of host tissues are associated with a morphogenic switch

191 from yeast-like to filamentous growth, which can be induced by changes in environmental 
192 conditions, such as shifts in temperature and $\mathrm{pH}$ (Berman and Sudbery 2002).

193 C. albicans history is intimately linked with the history of humans. Phylogenetic data

194 suggest that its diversification occurred $\sim 3$ to 16 MYA and coincided with the evolution of early

195 hominids (Lott et al. 2005). Moreover, it is believed that humans are the main environmental

196 reservoir of C. albicans (Angebault et al. 2013). In contrast to C. albicans, P. aeruginosa is a

197 ubiquitous microbe that can be isolated from diverse environments, including humans (Lister,

198 Wolter, and Hanson 2009). However, unlike C. albicans, it is rarely a member of the normal

199 microbial flora in humans. Instead, it is a causal agent of community-acquired and, more often,

200 nosocomial infections in individuals who are immunocompromised or suffered a breach in

201 cutaneous or mucosal barriers. The recently observed rise in opportunistic $P$. aeruginosa

202 infections appears to be related to the ability of this microbe to rapidly develop multidrug-

203 resistant phenotypes.

204 Mixed infections in which $P$. aeruginosa coexists with $C$. albicans often occur in patients

205 with burn wounds (Gupta et al. 2005) and chronic lung diseases (Hughes and Kim 1973). In

206 such infections the two organisms display an array of antagonistic interactions centered on

207 competition for the host resources and mediated by several mechanisms. For example, $C$.

208 albicans responds to the $P$. aeruginosa quorum-sensing signal 3-oxo-C12 homoserine lactone

209 (3OC12HSL) as well as its 12 carbon chain analogs C12HSL and dodecanol with the inhibition

210 of yeast cell filamentation and conversion of previously formed filaments to yeast cells (Hogan,

211 Vik, and Kolter 2004). These are likely defensive responses, as P. aeruginosa can attach to the

212 surface of C. albicans hyphae and kill them through the action of phospholipase $\mathrm{C}$ and

213 phenazines; yeast cells are not susceptible to P. aeruginosa attachment (Hogan and Kolter 2002;

214 Gibson, Sood, and Hogan 2009). 
216 were considered to be purely coincidental as these molecules share structural similarity with

217 farnesol. Farnesol is the $\mathrm{C} 12$ autoregulatory molecule that controls yeast-to-hypha transition in

218 C. albicans (Hogan, Vik, and Kolter 2004) by modulating cyclic AMP signaling through direct

219 inhibition of the adenylate cyclase activity (Davis-Hanna et al. 2008; Lindsay et al. 2012; Hall et

220 al. 2011) and suppressing filamentation of yeast cells (Hornby et al. 2001). Recent studies

221 revealed that despite structural similarities among the C12 HSLs and their analogs, only

222 3OC12HSL mimics farnesol's activity by interacting with the adenylate cyclase. Another C12

223 compound, dodecanol prevents yeast-to-hypha transition through a different mechanism

224 involving the transcriptional hyphal suppressor Sfl1p (Hall et al. 2011). Interestingly, dodecanol

225 shares structural similarity with a diffusible signal factor of Burkholderia cenocepacia (Hall et

226 al. 2011), which also interferes with C. albicans filamentation (Boon et al. 2008). Like $P$.

227 aeruginosa, representatives of the $B$. cepacia complex frequently coexist and interact

228 antagonistically with C. albicans in mixed infections of patients who are immunocompromised

229 and suffer chronic lung disease (Kerr 1994). Notably, however, C. albicans does not seem to

230 respond to C8 HSL, the major quorum-sensing signal produced by B. cepacia (Hogan, Vik, and

231 Kolter 2004; Boon et al. 2008).

In addition to autoregulation of fungal morphogenesis, farnesol plays a role in

233 interactions with bacterial antagonists by inhibiting biosynthesis of the P. aerugionosa quinolone

234 signal (PQS) and the PQS-controlled biosynthesis of the pyocyanin siderophore virulence factor

235 (Cugini et al. 2007). Moreover, C. albicans interferes with P. aeruginosa signaling and

236 metabolite production. It can also inhibit virulence of $P$. aeruginosa in mice by inhibition of

237 bacterial pyochelin and pyoverdine siderophore biosynthesis (Lopez-Medina et al. 2015). 
While the structural similarity of compounds that suppress yeast-to-hypha transition in $C$.

239 albicans may suggest ecological fitting, the diversity of the morphogenic mechanisms utilized by

240 C. albicans to respond to these bacterial C12 signal molecules as well as the complex interplay

241 of inhibitory interactions between C. albicans and its bacterial antagonists suggest that these

242 organisms may have been undergoing reciprocal selection within the context of human disease.

243 This process is expected to intensify with the continued increase in the number of patients who

244 require immune system suppression.

246 C. Mycophagy and biological control of fungi by bacteria

247 Fungal hyphae are a potential nutrient and energy source for bacteria. Some bacteria seem to be 248 specialized in feeding on fungi and have been considered mycophagous (Leveau and Preston 249 2008). They have been studied mainly as potential biological control agents aimed toward plant 250 pathogenic fungi (Jochum, Osborne, and Yuen 2006; Yoshida et al. 2012; Selin et al. 2010).

251 These antagonistic bacteria can kill the fungus using a combination of enzymes and antifungal 252 compounds. A well-studied and interesting antifungal compound produced by Lysobacter is 253 HSAF (heat-stabile antifungal factor), a hybrid PKS-NRPS inhibiting the fungal acyl-CoA254 dependent ceramide synthase, an enzyme unique to filamentous fungi ( $\mathrm{Li}$ et al. 2008; Yu et al. 255 2007). This inhibition affects the formation of lipid rafts that are important for proper fungal 256 exocytosis and endocytosis (Li et al. 2006; Alvarez, Douglas, and Konopka 2007).

257 Importantly, most potential biological control organisms have been selected for their 258 ability to produce antifungal compounds on agar plates but it is unclear if they also use the 259 fungus as an energy or carbon source or, indeed, if the same inhibiting compounds are active as 260 biocontrol agents in the natural environments (Thrane et al. 2000). Moreover, it is not necessary 
for mycophagous bacteria to lyse the fungal hyphae in order to parasitize the fungus, proliferate,

262 and inhibit the fungus efficiently. Some bacteria kill the fungus and multiply without penetrating

263 its cell walls, while others proliferate without any negative effects to the fungus (Cuong et al.

264 2011).

265 With the advent of transcriptomics and proteomics, new insights have been gained into these antagonistic of interactions. For example, dual transcriptomic studies of both the fungus and the bacterium challenging each other on agar plates focused on interactions between Aspergillus niger and Collimonas fungivorans (Mela et al. 2011) as well as Rhizoctonia solani and Serratia plymuthica (Gkarmiri et al. 2015; Neupane et al. 2015). In these studies, the 270 partners were not allowed to come into physical contact but could exchange metabolites, and in both cases the portion of the fungal colony that was transcriptionally profiled was the one adjacent to the inhibition zone. Both studies found that the fungi reacted by upregulating defense

273 responses (detoxification, efflux pumps), changes to membrane permeability, and increased

274 oxalate production. In contrast, the only response common in bacteria was the upregulation of 275 genes involved in production of secondary metabolites (Mela et al. 2011; Gkarmiri et al. 2015).

276 The two interactions were in many other ways quite different. The Aspergillus-Collimonas 277 interaction was mainly characterized by a competition for nitrogen (Mela et al. 2011), while the Rhizoctonia-Serratia interaction involved a mutual chemical warfare, as both the fungus and the

279 bacteria upregulated transcription of genes responsible for secondary metabolites/toxins and 280 defenses (Gkarmiri et al. 2015; Neupane et al. 2015).

Another example of fungal-bacterial antagonistic interactions comes from Magnaporthe 282 oryzae transcriptional responses after direct contact with Lysobacter enzymogenes, both a wild type (WT) strain and a mutant strain deficient in virulence (Mathioni et al. 2013). Four 
Magnaporthe genes were induced at 3 hours by both WT and mutant bacteria, and two of these were known stress response genes (a laccase and a beta-lactamase). The hypothesis that WT $L$. enzymogenes is capable of turning off fungal defenses while the mutant could not was used to interpret the data. A total of 463 Magnaporthe genes were down-regulated by WT $L$. enzymogenes. Of these genes, 100 were up-regulated in interaction with the non-virulent mutant and assumed to be genes involved in the fungal general response/defense against bacteria. These genes are predicted to have roles in carbohydrate metabolism, cellular transport and stress response (Mathioni et al. 2013).

The examples discussed above offer glimpses into the vast and complex world of metabolic activities involved in trophic interactions between bacteria and fungi, as we are only starting to uncover and understand these food webs. Clearly, further sustained efforts are needed to identify the players and understand the flows of energy and nutrients that support the communities of fungi and bacteria forming such trophic networks.

D. Fungal predation and dependence on bacteria

299 Fungi can attack, degrade, and use bacteria as nutrient sources (Barron 1988; Barron 2003).

300 These capabilities have mainly been noted in basidiomycete wood decomposers, with nitrogen limitation being the main trigger of fungal predation on bacteria (Barron 2003). Wood

302 decomposing fungi have profound effects on bacterial composition of the substrate they colonize 303 and the bacterial composition becomes characteristic for the fungal species colonizing the 304 substrate (Tornberg, Bååth, and Olsson 2003; de Boer et al. 2005). Along similar lines, nitrogen 305 fixation by bacteria seems to be important in wood decay and it has been suggested that nitrogen306 fixing bacteria grow on the low molecular carbon released by the wood decaying fungi and that 
the fungus then selectively harvests and degrades some of the bacteria as a source of nitrogen (de

308 Boer and van der Wal 2008). This idea has found support in a study of the nifH dinitrogenase

309 reductase diversity in dead wood, where a non-random co-occurrence pattern between nitrogen-

310 fixing bacteria and fungal species was detected, indicating specific interactions between fungi

311 and bacteria (Hoppe et al. 2014). Similarly, Rhizobium-type nitrogen-fixing bacteria can form

312 biofilms on fungi and this seems to affect the activity and survival of both organisms

313 (Seneviratne and Jayasinghearachchi 2003; Seneviratne et al. 2008).

314 Of relevance to the observations on the trophic interactions between fungi and bacteria is

315 the concept of bacteria farming by fungi, which was recently introduced to describe the

316 relationship between the fungus Morchella crassipes and Pseudomonas putida (Pion et al. 2013).

317 M. crassipes disperses bacteria, rears them on fungal exudates as well as harvests and

318 translocates bacterial carbon (Pion et al. 2013). It is possible that a similar mechanism of

319 bacteria farming by fungi can be behind the observed interactions between nitrogen-fixing

320 bacteria and fungi and could account for the apparent stability of the interactions.

Finally, not all trophic interactions involving fungi and bacteria are antagonistic. An

322 example of a more complex interaction comes from the cow dung-inhabiting bacterium

323 Stenotrophomonas maltophila. These bacteria are consumed by the bacterivorous nematode

324 Caenorhabditis elegans. As a defense mechanism, the bacteria secrete urea that mobilizes the

325 nematophagous fungus Arthrobotrys oligospora to respond to the nematode presence and

326 eliminate them. Nematode elimination is accomplished by the increased production of sticky

327 hyphal nets that trap and kill nematodes, which are then consumed by the fungus (Wang et al.

328 2014; Hsueh et al. 2013). 
Like with trophic interactions in which bacteria feed on fungi, fungal predation and

330 farming of bacteria are most likely widespread and underappreciated features of terrestrial

331 ecosystems. While some of them can be readily reproduced under laboratory conditions, others

332 need to be studied in situ in their natural environments to understand how they connect to more

333 conventional food webs.

335 E. Highways carrying hyphae-associated bacteria

336 Fungal hyphae expanding in and through unsaturated soil can spread in a soil volume easier than

337 bacteria, as they can bridge over aerial pores and other hydrophobic regions (Kohlmeier et al.

338 2005). The surfaces of the fungus assimilatory hyphae are hydrophilic and thus the fungal

339 hyphae form hydrophilic tracks through soil. These tracks are referred to as fungal highways

340 that the bacteria can follow and are generally regarded as beneficial to both the host and the

341 bacterial symbionts (Kohlmeier et al. 2005). The fungal highways have been studied in relation

342 to dissemination of pollutant-degrading bacteria (Kohlmeier et al. 2005; Furuno et al. 2010). In

343 particular, it has been shown that the fungal hyphae might not just help to spread the bacteria but

344 could also function as conduits of pollutants to bacteria (Banitz et al. 2014; Furuno et al. 2010;

345 Wick et al. 2007). In this respect, substrate is channeled from a source along the hyphae to

346 bacteria that are associated with these hyphae. The fungal host seems to nourish the bacterial

347 symbionts inhabiting and spreading on the highways (Bravo et al. 2013; Nazir et al. 2013). The

348 number of bacterial taxa associating and travelling along the fungal highways is probably a

349 combination of selection for the specific prevalent conditions, available substrates, and also by

350 direct activities of the host, e.g. a consequence of mutualist recognition or absence of parasite

351 recognition. Bacterial motility by flagella as well as other types of motility have been suggested 
352 as a common characteristic of bacteria travelling on the fungal highways (Bravo et al. 2013).

353 Among bacterial taxa especially common in the hyphosphere is the genus Burkholderia (Suárez-

354 Moreno et al. 2012). Interestingly, the same genus is also prominent among fungal

355 endosymbionts (see sections below). Fungus-derived oxalate and glycerol have been shown to

356 feed both mutualistic and parasitic bacterial symbionts living and spreading on the fungal

357 highways (Bravo et al. 2013; Nazir et al. 2013). It has also been shown that some bacteria that

358 migrate as "hitchhikers" along fungal highways can only do this if other bacteria have paved the

359 way for them (Warmink et al. 2011). Interestingly, such facilitation does not apply to all bacteria

360 (Warmink et al. 2011). Thus there appear to be three categories of bacteria in relation to

361 movement along fungal hyphae: (1) independent travelers that manage to set up the conditions

362 with the fungal hosts necessary for travel, (2) hitchhikers dependent on the simultaneous

363 presence of the independent travelers, and (3) non-travelers, either not having the properties,

364 such as motility, to move along the fungal highway, or being inhibited by the fungal host and/or

365 the first two types of travelers.

366 The potential importance of fungal highways to the soil bacteria suggests that these

367 interactions may be a common and, until recently, overlooked feature of soil ecosystems.

368 Consequently, the diversity of both fungi that serve as the thoroughfares and their bacterial

369 travelers requires in-depth surveying. The approach of symbiotic network reconstruction appears

370 to be a natural starting point for understanding the rules that govern highway usage. Importantly,

371 while bacterial travelers clearly benefit from highway availability, as it improves their mobility

372 in the soil and may offer a source of nourishment, it is unclear whether fungi receive any benefits

373 from this interaction. Is it a mutualism or an interaction in which the fungal partner remains

374 unaffected or perhaps even harmed? 
376 F. Mycorrhiza helper bacteria

377 Mycorrhizal fungi form with the roots of terrestrial plants symbiotic associations of distinct

378 morphologies and functions, collectively referred to as mycorrhizas (Smith and Read 2008). In

379 the most common among them, ecto- and arbuscular mycorrhizas, fungi facilitate plant mineral

380 nutrient uptake from the soil in return for photosynthetic carbon. As a consequence, these

381 symbioses are of great significance in both natural and managed ecosystems, with a particular

382 impact on agriculture and forestry. Current observations indicate that mycorrhizas are, in fact,

383 complex multipartner interactions (Bonfante and Anca 2009), due to the presence of bacteria that

384 can be either loosely or tightly associated with mycorrhizal fungi (Jansa, Bukovská, and

385 Gryndler 2013; Bianciotto et al. 2001; Perotto and Bonfante 1997). Garbaye (1994) pioneered

386 the work on these associations with the now widely accepted term mycorrhiza helper bacteria,

387 MHB, which defines bacteria that help mycorrhizal establishment. Since the time of MHB

388 discovery and thanks to the advent of the omics era, new knowledge and insights have

389 accumulated, with a particular focus on the microbiota present in the rhizosphere and endosphere

390 of poplar (Populus).

391 As a host for both ecto- and arbscular mycorrhizal fungi (AMF), poplar is an excellent

392 model for understanding interactions that govern establishment and functioning of mycorrhizal

393 symbioses, including the role of MHB. For example, the genomes of 21 strains of Pseudomonas

394 isolated from the Populus deltoides rhizosphere and endosphere have been sequenced (Brown et

395 al. 2012), giving rise to extensive genetic and bioinformatic resources. As a further step, these

396 bacterial isolates were screened for MHB effectiveness expressed as the effects on the Laccaria

397 bicolor $\mathrm{S} 238 \mathrm{~N}$ growth rate, mycelial architecture, transcriptional changes and symbiosis with 
three Populus lines, $P$. tremula $\times$ alba, $P$. trichocarpa, and $P$. deltoides. Nineteen of the studied

399 isolates had positive impact on L. bicolor growth (Labbé et al. 2014). Interestingly, one strain

400 promoted high root colonization also in $P$. deltoides, which is otherwise poorly colonized by $L$.

401 bicolor. In this context, the genome of a MHB isolate of Pseudomonas fluorescens BBc6R8 will

402 be of great advantage in identifying the helper traits (Deveau et al. 2014).

Prokaryotes are associated not only with the extraradical hyphae of mycorrhizal fungi,

404 but also with ectomycorrhizal roots and sporocarps, i.e., the fruiting bodies formed by

405 ectomycorrhizal ascomycetes and basidiomycetes, suggesting that they may accompany

406 mycorrhizal fungi during the various steps of their life cycle. Because of their economic

407 significance, Tuber sporocarps have become a model to understand a role that truffle-associated

408 bacteria play in several still poorly understood aspects of truffle development, from fruiting body

409 formation to aroma production. Similarly, the appearance of the "brûle", an area devoid of

410 vegetation around the Tuber host plants and where the fruiting bodies of T. melanosporum are

411 usually collected, is a feature with a clear ecological impact but largely unknown causes. For

412 example, the examination of direct fungal-fungal interactions (Napoli et al. 2010), together with

413 DGGE and DNA microarray analyses of 16S rRNA gene fragments (Mello et al. 2013), revealed

414 that the bacteria and archaeal communities strongly differ between the inside versus outside of

415 the brûlé area. The groups that were most severely affected by the black truffle included

416 Firmicutes, several genera of Actinobacteria, and a few Cyanobacteria. One of the mechanisms

417 responsible for this pattern could be the capacity of truffles to release volatile organic

418 compounds (Splivallo et al. 2011). Intriguingly, Splivallo et al. (2015) found that sulphur-

419 containing volatiles, such as thiophene derivatives characteristic of $T$. borchii fruiting bodies, are

420 products of the bacteria-mediated biotransformation of non-volatile precursor(s) into volatile 
421 compounds. Moreover, the $\alpha$ - and $\beta$-proteobacteria-dominated community of $T$. borchii was able

422 to produce thiophene volatiles from $T$. borchii fruiting body extract, irrespective of their isolation

423 source (truffle or other sources).

424 The complexity of interactions between fungi and both MHB and sporocarp-associated

425 bacteria makes them uniquely difficult to study. However, the tools of symbiotic network

426 construction and testing the applicability of the GMC model to these systems may provide

427 structured approaches to make rapid progress in understanding of these systems.

429 G. Recognition and assembly of the non-heritable symbionts to form the fungal-bacterial

430 metaorganism

431 Both plant and animal epithelial surfaces coming in contact with bacteria share a similar problem

432 in that they should actively select for beneficial/commensal bacteria and discourage the

433 colonization by antagonists (McFrederick et al. 2012; Artis 2008; Ausubel 2005; Zamioudis and

434 Pieterse 2012). Innate immunity recognition of bacterial cues as MAMPs (microbial associated

435 molecular patterns) plays a key role in this selection in both plants and animals (Artis 2008;

436 Nürnberger et al. 2004). However, the immune reaction is balanced so as not to kill eventual

437 beneficial bacteria, as is done in tissues not normally colonized by bacteria (Artis 2008;

438 Zamioudis and Pieterse 2012). Fungal hyphae growing in most natural environments face a

439 similar need to promote the beneficial and inhibit the antagonistic microbes. Fungal reactions to

440 a bacterial MAMP have been demonstrated (Xu et al. 2008), the existence of innate immunity

441 type recognition has been suggested (Paoletti and Saupe 2009; Paoletti, Saupe, and Clavé 2007),

442 and recently transcriptomic innate immunity type responses have been found in fungi (Ipcho et

443 al. 2016). Fungal innate immunity is thus most likely involved in the active selection for 
444 beneficial bacteria as it is in other eukaryotic hosts. The main mechanisms of such selection

445 involve production of antibiotics/secondary metabolites, selective provisioning of nutrients to the

446 beneficial bacteria (Huang et al. 2014; Hartmann et al. 2009; Ramírez-Puebla et al. 2013; Oozeer

447 et al. 2013; Scholtens et al. 2012), and creating conditions unfavorable for pathogens (Kai-

448 Larsen, Gudmundsson, and Agerberth 2014; Markel et al. 2007; Ramírez-Puebla et al. 2013).

449 The selective recruitment of beneficial bacteria is further helped by their either passive or active

450 transfer between host generations (Oozeer et al. 2013; Scholtens et al. 2012; Ramírez-Puebla et

451 al. 2013), thus resembling heritable transmission.

452 Interestingly, several mechanisms appear to be shared by diverse host symbiont-systems

453 (Table 1). For example, the gut epithelium, the rhizoplane, and the hyphosphere are typically

454 low-pH environments and this $\mathrm{pH}$ decrease is stimulated further by bacterial presence (Ramírez-

455 Puebla et al. 2013), a condition also shared by animal tissue inflammation (Rajamäki et al.

456 2013). Another key reaction in innate immunity is active sequestration of iron by the plant and

457 animal hosts (Markel et al. 2007; Ganz 2009; Ong et al. 2006; Lemanceau et al. 2009). As a

458 consequence, iron levels are much depleted both in the rhizosphere (Lemanceau et al. 2009) and

459 in the gut (Ganz 2009; Markel et al. 2007; Ong et al. 2006). Beneficial bacteria appear to be

460 adapted to such low-iron conditions and display either very low demand for iron, as the probiotic

461 Lactobacillus plantarum (Archibald 1983), or have very efficient siderophores, like many plant

462 growth-promoting rhizobacteria (Beneduzi, Ambrosini, and Passaglia 2012). Interestingly, most

463 genes involved in iron acquisition are also rapidly upregulated in Fusarium graminearum in

464 response to bacterial MAMPs (Ipcho et al. 2016). Finally, beneficial bacteria in the rhizosphere

465 are stimulated by plant rhizosphere-specific sugars, like raffinose and sucrose (Huang et al.

466 2014), which are generally not present in the soil, while beneficial gut bacteria in mammals are 
stimulated by fructans (Oozeer et al. 2013; Scholtens et al. 2012). Fungi interacting with

468 bacteria have been also shown to secrete carbon sources, such as oxalate (Scheublin et al. 2010),

469 glycerol (Nazir et al. 2013) and trehalose (Deveau et al. 2010), which could possibly serve

470 similar selective functions for beneficial bacteria.

471 The mechanisms responsible for the assembly of fungal-bacterial metaorganisms thus

472 appear to have parallels with other eukaryotic-bacterial metaorganisms and much can be learnt

473 from these other systems. Because fungi are relatively easy to study and manipulate genetically,

474 there is a great potential for rapid progress in understanding the fungal-bacterial interactions.

475 Importantly, we expect that all horizontally transmitted bacterial symbionts as well as the

476 bacteria engaged in heritable facultative mutualisms with fungi need to employ these

477 mechanisms when initiating the interaction with their hosts.

\section{Vertical Transmission and the Evolution of Mutualisms}

480 Because of its role in coupling of partner reproductive interests, vertical transmission is widely

481 recognized as a mechanism that stabilizes mutualisms under several evolutionary models,

482 including byproduct cooperation (Connor 1986; Sachs et al. 2004), IPD with the "tit-for-tat"

483 strategy (Axelrod and Hamilton 1981; Doebeli and Knowlton 1998; Sachs et al. 2004), PFF (Bull

484 and Rice 1991; Sachs et al. 2004; Weyl et al. 2010), and compensatory evolution/addiction

485 (Aanen and Hoekstra 2007). In addition, vertical transmission is expected to play an important

486 part in evolution of antagonistic interspecific interactions into mutualisms (Yamamura 1993).

487 Evolutionary theory predicts that a symbiotic system will transition from antagonism to

488 mutualism once a parasite is able to dominate the co-evolutionary race with the host and achieve

489 a rate of vertical transmission that enables efficient reciprocal selection between the partners 
490 (Yamamura 1993) (Fig. 2). If the increase in the rate of symbiont vertical transmission is

491 accompanied by the development of host abilities to complement its metabolism using symbiont

492 metabolites, a byproduct mutualism is expected to evolve (Yamamura 1993).

493 While the model that explains the evolution of mutualisms from antagonisms through

494 changes in the rates of symbiont transmission is rather straightforward (Yamamura 1993), the

495 actual mechanisms that permit symbiont vertical transmission remain elusive as nearly all known

496 heritable endosymbionts are uncultivable (Moran, McCutcheon, and Nakabachi 2008) and many

497 hosts are unable to survive without their endobacteria. In this context, the rice seedling blight

498 fungus Rhizopus microsporus and its endosymbiont Burkholderia rhizoxinica offer an

499 unprecedented opportunity to understand the evolution of mutualisms from antagonisms

500 (Partida-Martinez and Hertweck 2005; Lackner and Hertweck 2011). In this system, the

501 endobacteria reside directly within the fungal cytoplasm (Partida-Martinez et al. 2007). Their

502 elimination with antibiotics abolishes fungal ability to form asexual sporangia and

503 sporangiospores (Partida-Martinez et al. 2007), suggesting that endobacteria not only gained

504 control of their own transmission rate but also of the reproductive success of the fungus, a

505 pattern consistent with the compensatory evolution/addiction model of mutualism evolution

506 (Aanen and Hoekstra 2007). In addition to controlling the rate of own vertical transmission by

507 rendering fungal reproduction dependent on their presence, the endobacteria produce a macrolide

508 metabolite that is processed by the host to form a highly potent antimitotic toxin called rhizoxin

509 (Scherlach et al. 2012). The toxin is active in rice seedlings, where it causes the blight disease

510 (Lackner, Partida-Martinez, and Hertweck 2009). In addition, rhizoxin is believed to facilitate

511 competitive interactions of the Rhizopus host with fungi that are sensitive to it. Such positive

512 effects of the symbiont-derived metabolite on host fitness suggest that the Rhizopus- 
513 Burkholderia symbiosis can be viewed as a byproduct mutualism, in addition to being an

514 example of the addiction model. The Rhizopus host, like other Mucorales, is protected from

515 harmful effects of the toxin by a specific mutation in its $\beta$-tubulin gene (Schmitt et al. 2008).

516 The presence of this protective mutation across other Mucorales suggests that it was a

517 preadaptation that allowed Rhizopus for entering a byproduct mutualism with the Burkholderia

518 endobacteria.

519 The $3.75 \mathrm{Mb}$ genome of B. rhizoxinica appears to be moderately sized compared to free-

520 living Burkholderia with genomes of $8-9 \mathrm{Mb}$ (Winsor et al. 2008), but is considerably larger

521 than the genomes of closely related endosymbiotic $\beta$-proteobacteria, including Candidatus

522 Glomeribacter gigasporarum (1.72 Mb) (Ghignone et al. 2012), the unnamed endosymbiont of

523 Mortierella elongata (2.65 Mb) (Fujimura et al. 2014), and Ca. Tremblaya princeps (0.14 Mb)

524 (McCutcheon and von Dohlen 2011). Such reductions in the endosymbiont genome size are

525 associated with the process of adaptation to the host cellular environment (McCutcheon and

526 Moran 2012). Nevertheless, the Burkholderia endobacteria of Rhizopus remain not only

527 metabolically independent of the host and but also capable of invading compatible hosts de novo

528 (Moebius et al. 2014). In particular, the release of bacterial chitinolytic enzymes and chitin-

529 binding proteins enables breaching of fungal cell walls and the initiation of the invasion process

530 (Moebius et al. 2014). In turn, the survival and proliferation of $B$. rhizoxinica inside fungal cells

531 appears to depend on the activity of the type III secretion system (Lackner, Moebius, and

532 Hertweck 2011), and the presence of a specific O-antigen in the lipopolysaccharides, LPS, that

533 make up the outer membrane of these Gram-negative bacteria (Leone et al. 2010). It is not

534 affected, however, by the structural changes in the exopolysaccharide, EPS, secreted matrix

535 (Uzum et al. 2015). 
Even though some of the features displayed by the Rhizopus-Burkholderia symbiosis are

537 typical for a mutualism, the Burkholderia endobacteria appear to be facultative endosymbionts,

538 capable of living both inside and outside eukaryotic cells, a lifestyle similar to that of pathogenic

539 Legionella, Salmonella, or Bartonella. This duality, combined with the ease of experimental

540 manipulation, propelled the Rhizopus-Burkholderia symbiosis to become a model for studying

541 the evolution of heritable symbioses. In particular, addressing questions concerning its

542 evolutionary origins, whether it started with the partners interacting as antagonists (Fig. 2), and

543 whether it has already achieved evolutionary stability (Fig. 3) will be a source of rich insights not

544 only into the genetic mechanisms of symbiont vertical transmission but also into other facets of

545 partner coevolution.

546

547 V. Heritable Symbiotic Interactions

548 A. Introduction

549 As discussed in the preceding sections, symbiont vertical transmission is a principal factor

550 contributing to both the establishment and stability of mutualisms. Importantly, vertical

551 transmission is not exclusive to mutualisms; it can also occur in antagonistic interactions.

552 Vertical transmission can be strict or mixed. In strict vertical transmission symbionts are

553 transferred from a parent exclusively to offspring. In mixed transmission, in addition to being

554 passaged between generations, symbionts move horizontally between members of the same

555 generation. Symbioses with strict vertical transmission are characterized by congruity of partner

556 phylogenetic histories, consistent with partner codiversification (Page 2003). In symbioses with

557 mixed transmission, the extent of horizontal transmission determines the degree of incongruity

558 between partner phylogenies. Interestingly, strict vertical transmission of symbionts tends to be 
associated with reciprocally obligate partner dependence, whereas mixed transmission is found

560 in associations in which either one or both partners are facultatively dependent on the symbiosis

561 (Fig. 3).

562 Importantly, while in fungi all known heritable associations involve endobacteria that

563 reside inside fungal cells, not all associations formed by fungi with endobacteria are known to be

564 heritable. In heritable symbioses, bacteria are either facultatively or obligately dependent on the

565 fungus. The Burkholderia symbionts of Rhizopus, discussed in the previous section, as well as

566 Rhizobium radiobacter in the root-colonizing Piriformospora indica (Sharma et al. 2008)

567 represent facultative heritable endobacteria. In contrast, obligate heritable endosymbionts

568 include two groups of bacteria associated with AMF, $\mathrm{Ca}$. Glomeribacter gigasporarum

569 (Bianciotto et al. 2003) and the mycoplasma-related endobacteria, MRE (Naumann, Schüßler,

570 and Bonfante 2010). It is unclear whether the unnamed heritable endosymbiont of Mortierella

571 elongata (Sato et al. 2010) is a facultative or obligate endobacterium. Remarkably, we are not

572 aware of heritable fungal-bacterial symbioses in which the interacting partners are obligately

573 dependent on each other. Such associations are common in insects, which depend on

574 endobacteria for provision of essential nutrients (McCutcheon and Moran 2012). It remains to

575 be investigated whether this knowledge gap represents a true dearth of reciprocally obligate

576 fungal-bacterial interactions or a detection bias. Recent accumulation of newly discovered

577 associations that involve non-heritable endobacteria suggests that the latter might be the case.

578 Such non-heritable associations include, among others, Helicobacter pylori in Candida albicans

579 (Siavoshi and Saniee 2014), Nostoc punctiforme in Geosiphon pyriforme (Schüßler et al. 1994),

580 Bacillus spp. in Ustilago maydis (Ruiz-Herrera et al. 2015), $\alpha$-proteobacteria in the

581 ectomycorrhizal fungus Laccaria bicolor (Bertaux et al. 2005; Bertaux et al. 2003), and diverse 
582 bacteria that inhabit hyphae of phylogenetically diverse fungal endophytes of plants (Hoffman

583 and Arnold 2010). Due to the lack of sufficient data from other systems, our discussion in the

584 following two sections will focus on $\mathrm{Ca}$. Glomeribacter gigasporarum and MRE associated with

585 AMF.

586

587 B. Heritable facultative mutualisms

$588 \mathrm{Ca}$. Glomeribacter gigasporarum, referred hereafter as Glomeribacter, is a stable, and

589 structurally integrated endosymbiont found in many representatives of the AMF family

590 Gigasporaceae (Bianciotto, Bandi, et al. 1996; Bianciotto et al. 2003; Mondo et al. 2012). It

591 thrives inside the fungal cells along the different stages of the fungal life cycle, always located

592 inside a compartment structurally resembling a fungal vacuole (Bianciotto, Minerdi, et al. 1996).

593 On the fungal side, the Gigasporaceae, like other AMF, form symbiotic associations with roots

594 of many plants, and may proliferate also in the absence of the endobacteria (Lumini et al. 2007),

595 giving rise to an association that is obligate for the bacterial partner and facultative for the fungal

596 host. A similar disparity is true for all AMF, as they fully depend on their host plants for energy,

597 while plants may complete their life cycle in the absence of AMF.

598 While biodiversity studies have demonstrated that Glomeribacter is widespread, they

599 have not identified factors responsible for the evolutionary stability of the Gigasporaceae-

600 Glomeribacter symbiosis, which dates back to the early Devonian (Mondo et al. 2012). The

601 Glomeribacter genome sequencing revealed that this endobacterium has a reduced genome of

$6021.7 \mathrm{Mb}$ (Ghignone et al. 2012), consistent with its uncultivable status (Jargeat et al. 2004). It

603 lacks metabolic pathways leading to important amino acids, but has many amino acid permeases

604 for uptake of nutrients from the fungus, as expected of an endobacterium that depends on its host 
for nutrients and energy (Fig. 4). Interestingly, the whole operon for biosynthesis of vitamin B12

606

607

608

609

610

611

613

614

615

616

617

618

619

620

621

622

623

624

625

626

627

is present in the Glomeribacter genome, but it is not clear whether this might represent any benefit for the fungus. In contrast to animals, which use B12-dependent enzymes for methionine synthesis and methylmalonate metabolism, fungi and land plants rely on B12-independent enzymes for these pathways (Young, Comas, and de Carvalho 2015). Consistent with this expectation, the genome of a model AMF, Rhizophagus irregularis, encodes B12-independent enzymes (Tisserant et al. 2013).

While the significance of Glomeribacter to the AMF hosts could not be gleaned from its genomic sequence, the availability of a stable endosymbiont-free AMF Gigaspora margarita BEG34 line, designated as B(-), allowed for direct comparisons with the line containing the endobacterium, $\mathrm{B}(+)$. These comparisons revealed several differences, both phenotypic (Lumini et al. 2007) and transcriptional (Salvioli et al. 2016), that speak to the role of Glomeribacter in the AMF host. For example, the B(-) AMF line was able to colonize its plant host but was impaired in mycelial growth and spore production compared to the $\mathrm{B}(+)$ line (Lumini et al. 2007). Moreover, benefits of the endosymbiont presence appeared to extend to the plant host, as the phosphate measurements in Lotus japonicus plants revealed a statistically higher phosphate quantity in the symbiosis established by the $\mathrm{B}(+)$ versus the $\mathrm{B}(-)$ AMF line (Salvioli et al. 2016). In turn, the transcriptome analysis showed that the endobacterium had a stronger effect on the pre-symbiotic phase of the fungus, supporting earlier phenotypic observations that Glomeribacter promotes germ tube extension in the AMF host (Lumini et al. 2007; Salvioli et al. 2016). Coupling of transcriptomics with physiological and cell biology approaches demonstrated that the bacterium increases the AMF sporulation success, raises the AMF bioenergetic capacity, increasing ATP production, and elicits mechanisms to detoxify reactive 
oxygen species (Salvioli et al. 2016). Moreover, application of the TAT (transactivator of

629 transcription) peptide to translocate the bioluminescent calcium reporter aequorin revealed that

630 the $\mathrm{B}(+) \mathrm{AMF}$ line had a lower basal intracellular calcium concentration than the $\mathrm{B}(-)$ line,

631 indicating that the endobacterium affects a large number of fungal cell functions, including

632 calcium metabolism, consistent with a potential role as a storage compartment for intracellular

633 calcium. Finally, the fungal mitochondrion and its main metabolic pathways (ATP synthesis,

634 respiration) appear to be important targets of the bacterial presence. Interestingly, the AMF

635 mitochondria are also the first target of strigolactones, the plant hormones that play a key role in

636 plant-fungal signaling (Al-Babili and Bouwmeester 2015; Bonfante and Genre 2015). In the

637 experiments where the $\mathrm{B}(+)$ and $\mathrm{B}(-) \mathrm{AMF}$ lines were treated with a synthetic strigolactone,

638 GR24, the bacteria seemed to react to strigolactones, in agreement with data demonstrating the

639 GR24 treatment induces bacterial cell division (Anca et al. 2009). All these experiments,

640 confirmed by an extensive proteomic analysis (Vannini et al. 2016 ), revealed that the bacterium,

641 directly or indirectly, affects the oxidative status of the fungus. Moreover, these benefits appear

642 to be transmitted to the host plants (Vannini et al. 2016 ).

643 Collectively, although Glomeribacter exacts a nutritional cost on the AMF, the symbiosis

644 appears to improve the fungal fitness by priming mitochondrial metabolic pathways and

645 provisioning AMF with the tools to face environmental stresses. These observations suggest that

646 evolutionary stability of the Gigasporaceae-Glomeribacter mutualism could be best explained by

647 the PFF model (Bull and Rice 1991; Sachs et al. 2004; Weyl et al. 2010), as, at present, there are

648 no indications that non-cooperative partners are sanctioned in this system, a pattern expected

649 under the IPD model (Axelrod and Hamilton 1981; Doebeli and Knowlton 1998; Sachs et al.

650 2004). Neither there is evidence for byproduct cooperation (Connor 1986; Sachs et al. 2004) or 
661

662

compensatory evolution/addiction (Aanen and Hoekstra 2007).

Despite the remarkable progress made recently in understanding the Gigasporaceae-

Glomeribacter symbiosis, there are many outstanding questions. For example, it remains unclear what factors keep this association from evolving towards reciprocally obligate partner dependence predicted by evolutionary theory (Fig. 3). It could be speculated that the benefits to the AMF host depend on the environmental context and the association may break up when the cost of supporting the endosymbiont becomes prohibitive. This scenario would explain why the endobacteria in the Gigasporaceae-Glomeribacter symbiosis appear to retain the potential to transmit horizontally and exchange genes, attributes that may have contributed to their evolutionary longevity (Mondo et al. 2012).
C. Heritable antagonisms

The symbiosis between AMF and MRE (mycoplasma related endobacteria) represents an outstanding deviation from the molecular evolution patterns both expected by evolutionary models and detected thus far in heritable endobacteria (McCutcheon and Moran 2012), including Glomeribacter (Mondo et al. 2012). In particular, MRE display extraordinary intra-host diversity of their 16S rRNA gene (Naumann, Schüßler, and Bonfante 2010; Desirò et al. 2014; Desirò et al. 2015; Toomer et al. 2015) and genomic sequences (Naito, Morton, and Pawlowska 2015; Torres-Cortés et al. 2015). In part, this diversity could be attributed to a high mutation rate, related to the loss of DNA repair machinery from the MRE genomes, combined with the apparent activity of mechanisms contributing to genome plasticity, such as recombination machinery and mobile genetic elements (Naito, Morton, and Pawlowska 2015; Naito and Pawlowska 2016). While the mechanisms responsible for genome plasticity are not expected to 
operate in heritable mutualists with strict vertical transmission, they have been detected in mutualists with mixed transmission (McCutcheon and Moran 2012), including Glomeribacter (Mondo et al. 2012). Notably, though, the extent of intra-host diversity displayed by MRE exceeds vastly the diversity exhibited by mutualists with mixed transmission (Naito and Pawlowska 2016). In fact, the co-ocurrence of MRE and Glomeribacter in several AMF allowed for direct comparisons of their rRNA gene diversity revealing that, while MRE sequences formed highly divergent sequence clusters, no diversity was apparent in Glomeribacter (Desirò et al. 2014; Toomer et al. 2015). This disparity in molecular evolution patterns between MRE and heritable mutualists with mixed transmission lead to the hypothesis that MRE may be parasites of AMF (Toomer et al. 2015). This hypothesis is built on the predictions of evolutionary models (Frank 1994, 1996, 1996) suggesting that hosts are expected to benefit from reduced mixing of endosymbiont lineages because genetically uniform endosymbionts are less likely to engage in competition that damages the host (Fig. 5). Bottlenecks imposed by vertical transmission on symbiont populations reduce symbiont diversity inside host individuals, and thus, vertical transmission is expected to limit destructive competition among symbionts for the host resources. On the other hand, decline in symbiont relatedness within a host is predicted to increase host exploitation and favor symbionts that are able to transmit horizontally to secure new hosts.

While ascertaining whether MRE are antagonists or mutualists of AMF requires empirical data, inferences about factors that contribute to evolutionary stability of the MRE association with AMF can be made from the molecular evolution patterns evident in their genomes. Given the high mutation rate apparent in MRE, it could be expected that they are vulnerable to genomic degeneration and extinction (McCutcheon and Moran 2012). Yet, co- 
697 divergence patterns between MRE and the two fungal lineages in which MRE occur, AMF and

698 the Endogone lineage of Mucoromycotina, suggest that the AMF-MRE association may predate

699 the divergence between these two lineages and thus be as old or older than the Gigasporaceae-

700 Glomeribacter symbiosis (Desirò et al. 2015; Toomer et al. 2015). It has been postulated that the

701 key factors that prevent MRE from extinction are the mechanisms responsible for genome

702 plasticity in MRE, including the recombination machinery and mobile genetic elements, (Naito,

703 Morton, and Pawlowska 2015; Naito and Pawlowska 2016). Despite these advances, MRE

704 remain an elusive group of endobacteria. Not only their role in the AMF host biology but also

705 the mechanisms of putative horizontal transmission require experimental evaluation.

\section{VI. Future Developments}

708 A. Introduction

709 The establishment and outcomes of the fungal bacterial interactions are most probably a result of

710 chemical communication where a compound from one partner elicits a response with another

711 compound from the other partner (Baruch et al. 2014; Piispanen and Hogan 2008; Xu et al. 2008;

712 Badri et al. 2009; Nazir et al. 2010; Schroeckh et al. 2009; Sengupta, Chattopadhyay, and

713 Grossart 2013). This is typical for "ping-pong" type communications, where a communication

714 from one interacting partner draws a response from the other partner (Griffin 2012). The correct

715 order of events in ping-pong communication, rather than unique metabolites, could be selective

716 and instrumental in establishing the relationship (like a combinatorial lock). With the advent of

717 modern omics, these ping-pong events could be studied using transcriptomics (Mela et al. 2011;

718 Gkarmiri et al. 2015; Neupane et al. 2015; Mathioni et al. 2013), proteomics (Moretti et al.

719 2010), and aided with metabolomics, allowing for hourly resolution of events during the 
720 establishment of the interaction. Although for multispecies bacterial communities colonizing

721 fungal hyphae this type of study is a major challenge, it would be possible to perform (Moretti et

722 al. 2012) and allow to test predictions of a theoretical model suggesting that complex microbial

723 communities could be stabilized by counteraction of antibiotic synthesis and degradation

724 conducted by different members of the community (Kelsic et al. 2015).

726 B. Novel tools to study fungal-bacterial metaorganisms

727 Recently developed technologies, like laser dissection and imaging mass spectrometry (IMS),

728 could be adapted to sample and analyze fungal-bacterial interaction at the microscopic level.

729 Laser dissection could be used to sample single bacterial cells or fungal nuclei from different

730 locations, and combined with single cell genomics/trancriptomics (Kang et al. 2015; Saliba et al.

731 2014; Teichert et al. 2012), reveal site-dependent activities of various bacteria. IMS (Watrous,

732 Alexandrov, and Dorrestein 2011) has been used to visualize the distribution of selected

733 chemicals such as non-ribosomal antifungal peptides produced in interactions between fungi and

734 bacteria (Michelsen et al. 2015). However, isolating natural fungal-bacterial partners is not

735 trivial and there is a need for new techniques, especially for isolating bacteria from fungal

736 surfaces. Some have already been developed and used to isolate bacteria from fungal highways

737 (Simon et al. 2015) or from floating mycelia (Cuong et al. 2011). Another challenge is to grow

738 natural fungal metaorganisms, since maintaining them on standard rich lab-media could interfere

739 with and break up the association, a problem also faced in highly context-specific lichen

740 metaorganisms (Verma and Behera 2015).

741

742 C. Physiological processes known from other host-symbiont systems 
743 In this section, we list a few physiological processes known from other host-microbe systems

744 that are also likely to be involved in fungal-bacterial interactions.

745 Extracellular vesicle trafficking: All organisms can produce extracellular vesicles (Deatherage

746 and Cookson 2012). In fungal pathogens of humans, these exosomes are important in

747 interactions with the host (Rodrigues et al. 2014), whereas in bacteria they play a role in biofilm

748 communication between cells (Remis et al. 2014; Kulp and Kuehn 2010) and interaction with

749 other bacteria (Kulp and Kuehn 2010; Vasilyeva et al. 2013).

750 Transfer of interfering RNA: Extracellular vesicles have been shown to sometimes carry small

751 RNA (Samuel et al. 2015) or DNA (Kulp and Kuehn 2010), which opens up possibilities for

752 interfering with partner organisms (Nicolás and Ruiz-Vázquez 2013).

753 Unconventional secretion: Fungi, like all eukaryotes, secrete proteins mainly through the ER-

754 Golgi pathway using N-terminal signal peptides to guide the proteins into the pathway. Proteins

755 without signal peptides can also be secreted through unconventional secretion pathways (Zhang

756 and Schekman 2013). These pathways are important during interaction between host and

757 microorganisms in both plant and animal systems (Ding, Robinson, and Jiang 2014; Öhman et al.

758 2014) and additionally also involved in the production of extracellular vesicles (Zhang and

759 Schekman 2013).

760 Priming of responses against pathogens by beneficial organisms: Beneficial bacteria are

761 recognized by similar systems as pathogens and can induce enhanced immune functions against

762 later attacks by pathogens, thus priming the defenses. Such priming responses are a hot topic in

763 both plant and animal systems (Chu and Mazmanian 2013; Conrath 2009; Aranega-Bou et al.

764 2014; Val et al. 2008) and can be expected to be important for both non-heritable and heritable

765 fungal bacterial interactions. 


\section{VII. Closing Remarks}

768 The recent explosion of newly discovered fungal-bacterial interactions suggests that they are

769 more common and important than previously thought. In addition to their significance in

770 ecosystem functioning, many fungal-bacterial associations are central to human health,

771 agriculture, forestry, and bioremediation. While some of these important symbioses are already

772 in the forefront of data gathering and interpretation, many still remain unknown because of the

773 microscopic scale of the interacting partners, the complexity of their communities, and the

774 intricate nature of the relations that connect them. The advent and expansion of new techniques,

775 which allow for exploration and characterization of microbiota in natural and man-made habitats,

776 carries a promise that these obscure systems will soon be discovered and understood at the level

777 achieved for macroorganisms and their interactions. Here, we hope that our discussion will

778 inspire both fungal biologists and prokaryotic microbiologists to develop cross-disciplinary

779 approaches allowing for discovery and characterization of novel links between fungi and

780 bacteria. Until microbiota-specific conceptual tools are established, these explorations could be

781 guided by ecological and evolutionary frameworks that already exist for interspecific interactions

782 among macroorganisms. Collectively, a combination of the omics approaches, genetic

783 experiments, and ecological and evolutionary tools will allow us to expand the knowledge of

784 fungal-bacterial biodiversity and understand the mechanisms underlying these inter-domain

785 interactions.

786

\section{Acknowledgements}

788 We thank Olga Lastovetsky for comments on the manuscript. This work was supported by the 
789 National Science Foundation grant IOS- 1261004 to TEP and the Torino University $60 \%$ grant to 790 PB 
792

793

794

795

796

797

798

799

800

801

802

803

804

805

806

807

808

809

810

812

813

\section{References}

Aanen, D. K., and T. Bisseling. 2014. Microbiology. The birth of cooperation. Science 345 (6192):29-30.

Aanen, D. K., and R. F. Hoekstra. 2007. The evolution of obligate mutualism: if you can't beat 'em, join 'em. Trends in Ecology \& Evolution 22 (10):506-509.

Al-Babili, S., and H. J. Bouwmeester. 2015. Strigolactones, a novel carotenoid-derived plant hormone. Annual Review of Plant Biology (66):161-186.

Alvarez, F. J., L. M. Douglas, and J. B. Konopka. 2007. Sterol-rich plasma membrane domains in fungi. Eukaryotic Cell 6 (5):755-763.

Anca, I. A., E. Lumini, S. Ghignone, A. Salvioli, V. Bianciotto, and P. Bonfante. 2009. The ftsZ gene of the endocellular bacterium 'Candidatus Glomeribacter gigasporarum' is preferentially expressed during the symbiotic phases of its host mycorrhizal fungus. Molecular Plant-Microbe Interactions 22 (3):302-10.

Angebault, C., F. Djossou, S. Abelanet, E. Permal, M. Ben Soltana, L. Diancourt, C. Bouchier, P.-L. Woerther, F. Catzeflis, A. Andremont, C. d'Enfert, and M.-E. Bougnoux. 2013. Candida albicans is not always the preferential yeast colonizing humans: A study in Wayampi Amerindians. Journal of Infectious Diseases 208 (10):1705-1716.

Aranega-Bou, P., M. D. Leyva, I. Finiti, P. García-Agustín, and C. González-Bosch. 2014. Priming of plant resistance by natural compounds. Hexanoic acid as a model. Frontiers in Plant Science 5:488.

Archibald, F. 1983. Lactobacillus plantarum, an organism not requiring iron. FEMS Microbiology Letters 19 (1):29-32. 
814 Artis, D. 2008. Epithelial-cell recognition of commensal bacteria and maintenance of immune 815 homeostasis in the gut. Nature Reviews Immunology 8 (6):411-420.

816 Ausubel, F. M. 2005. Are innate immune signaling pathways in plants and animals conserved? Nature Immunology 6 (10):973-979.

Axelrod, R., and W. D. Hamilton. 1981. The evolution of cooperation. Science 211 (4489):13901396.

Badri, D. V., T. L. Weir, D. van der Lelie, and J. M. Vivanco. 2009. Rhizosphere chemical dialogues: plant-microbe interactions. Current Opinion in Biotechnology 20 (6):642-650.

Banitz, T., K. Johst, L. Y. Wick, S. Schamfuss, H. Harms, and K. Frank. 2014. Highways versus pipelines: contributions of two fungal transport mechanisms to efficient bioremediation. Environmental Microbiology Reports 5 (4):211-218.

Barron, G. L. 1988. Microcolonies of bacteria as a nutrient source for lignicolous and other fungi. Canadian Journal of Botany 66 (12):2505-2510.

Barron, G. L. 2003. Predatory fungi, wood decay, and the carbon cycle. Biodiversity 4 (1):3-9.

Baruch, M., I. Belotserkovsky, B. B. Hertzog, M. Ravins, E. Dov, K. S. McIver, Y. S. Le Breton, Y. Zhou, C. Y. Cheng, and E. Hanski. 2014. An extracellular bacterial pathogen modulates host metabolism to regulate its own sensing and proliferation. Cell 156 (12):97-108.

Baschien, C., G. Rode, U. Boeckelmann, P. Goetz, and U. Szewzyk. 2009. Interactions between hyphosphere-associated bacteria and the fungus Cladosporium herbarum on aquatic leaf litter. Microbial Ecology 58 (3):642-650. Press. 
Beneduzi, A., A. Ambrosini, and L. M. P. Passaglia. 2012. Plant growth-promoting rhizobacteria (PGPR): Their potential as antagonists and biocontrol agents. Genetics and Molecular Biology 35 (4 Suppl):1044-1051.

Berman, J., and P. E. Sudbery. 2002. Candida albicans: a molecular revolution built on lessons from budding yeast. Nature Reviews Genetics 3 (12):918-30.

Bertaux, J., M. Schmid, P. Hutzler, A. Hartmann, J. Garbaye, and P. Frey-Klett. 2005. Occurrence and distribution of endobacteria in the plant-associated mycelium of the ectomycorrhizal fungus Laccaria bicolor S238N. Environmental Microbiology 7 (11):1786-1795.

Bertaux, J., M. Schmid, N. C. Prevost-Boure, J. L. Churin, A. Hartmann, J. Garbaye, and P. Frey-Klett. 2003. In situ identification of intracellular bacteria related to Paenibacillus spp. in the mycelium of the ectomycorrhizal fungus Laccaria bicolor S238N. Applied and Environmental Microbiology 69 (7):4243-4248.

Biagi, E., M. Candela, S. Fairweather-Tait, C. Franceschi, and P. Brigidi. 2012. Ageing of the human metaorganism: the microbial counterpart. Age 34 (1):247-267.

Bianciotto, V., S. Andreotti, R. Balestrini, P. Bonfante, and S. Perotto. 2001. Mucoid mutants of the biocontrol strain Pseudomonas fluorescens CHA0 show increased ability in biofilm formation on mycorrhizal and nonmycorrhizal carrot roots. Molecular Plant-Microbe Interactions 14 (2):255-60.

Bianciotto, V., C. Bandi, D. Minerdi, M. Sironi, H. V. Tichy, and P. Bonfante. 1996. An obligately endosymbiotic mycorrhizal fungus itself harbors obligately intracellular bacteria. Applied and Environmental Microbiology 62 (8):3005-3010. 
Bianciotto, V., E. Lumini, P. Bonfante, and P. Vandamme. 2003. 'Candidatus Glomeribacter gigasporarum' gen. nov., sp nov., an endosymbiont of arbuscular mycorrhizal fungi. International Journal of Systematic and Evolutionary Microbiology 53:121-124.

Bianciotto, V., D. Minerdi, S. Perotto, and P. Bonfante. 1996. Cellular interactions between arbuscular mycorrhizal fungi and rhizosphere bacteria. Protoplasma 193 (1-4):123-131.

Bonfante, P., and I. A. Anca. 2009. Plants, mycorrhizal fungi, and bacteria: a network of interactions. Annual Review of Microbiology 63:363-83.

Bonfante, P., and A. Genre. 2015. Arbuscular mycorrhizal dialogues: do you speak 'plantish' or 'fungish'? Trends Plant Sci 20 (3):150-4.

Boon, C., Y. Deng, L. H. Wang, Y. He, J. L. Xu, Y. Fan, S. Q. Pan, and L. H. Zhang. 2008. A novel DSF-like signal from Burkholderia cenocepacia interferes with Candida albicans morphological transition. ISME Journal 2 (1):27-36.

Bosch, T. C. G., and M. J. McFall-Ngai. 2011. Metaorganisms as the new frontier. Zoology 114 (4):185-190.

Bravo, D., G. Cailleau, S. Bindschedler, A. Simon, D. Job, E. Verrecchia, and P. Junier. 2013. Isolation of oxalotrophic bacteria able to disperse on fungal mycelium. FEMS Microbiology Letters 348 (2):157-166.

Broadbent, D. 1966. Antibiotics produced by fungi. Botanical Review 32 (3):219-242.

Brown, S. D., S. M. Utturkar, D. M. Klingeman, C. M. Johnson, S. L. Martin, M. L. Land, T. Y. S. Lu, C. W. Schadt, M. J. Doktycz, and D. A. Pelletier. 2012. Twenty-one genome sequences from Pseudomonas species and 19 genome sequences from diverse bacteria isolated from the rhizosphere and endosphere of Populus deltoides. Journal of Bacteriology 194 (21):5991-5993. 
Bull, J. J., and W. R. Rice. 1991. Distinguishing mechanisms for the evolution of cooperation. Journal of Theoretical Biology 149 (1):63-74.

Chu, H. T., and S. K. Mazmanian. 2013. Innate immune recognition of the microbiota promotes host-microbial symbiosis. Nature Immunology 14 (7):668-675.

Connor, R. C. 1986. Pseudo-reciprocity: investing in mutualism. Animal Behaviour 34:15621584.

Conrath, U. 2009. Priming of induced plant defense responses. Plant Innate Immunity 51:361395.

Cugini, C., M. W. Calfee, J. M. Farrow, 3rd, D. K. Morales, E. C. Pesci, and D. A. Hogan. 2007. Farnesol, a common sesquiterpene, inhibits PQS production in Pseudomonas aeruginosa. Molecular Microbiology 65 (4):896-906.

Cuong, N. D., M. H. Nicolaisen, J. Sørensen, and S. Olsson. 2011. Hyphae-colonizing Burkholderia sp.-A new source of biological control agents against sheath blight disease (Rhizoctonia solani AG1-IA) in rice. Microbial Ecology 62 (2):425-434.

Davis-Hanna, A., A. E. Piispanen, L. I. Stateva, and D. A. Hogan. 2008. Farnesol and dodecanol effects on the Candida albicans Ras1-cAMP signalling pathway and the regulation of morphogenesis. Molecular Microbiology 67 (1):47-62.

de Boer, W., L. B. Folman, R. C. Summerbell, and L. Boddy. 2005. Living in a fungal world: impact of fungi on soil bacterial niche development. FEMS Microbiology Reviews 29 (4):795-811.

de Boer, W., and A. van der Wal. 2008. Interactions between saprotrophic basidiomycetes and bacteria. In Ecology of Saprotrophic Basidiomycetes, edited by L. Boddy, J. C. Frankland and P. van West. San Diego, CA: Elsevier Academic Press Inc. 
Deatherage, B. L., and B. T. Cookson. 2012. Membrane vesicle release in bacteria, eukaryotes, and archaea: a conserved yet underappreciated aspect of microbial life. Infection and Immunity 80 (6):1948-1957.

Desirò, A., A. Faccio, A. Kaech, M. I. Bidartondo, and P. Bonfante. 2015. Endogone, one of the oldest plant-associated fungi, host unique Mollicutes-related endobacteria. New Phytologist 205 (4):1464-1472.

Desirò, A., A. Salvioli, E. L. Ngonkeu, S. J. Mondo, S. Epis, A. Faccio, A. Kaech, T. E. Pawlowska, and P. Bonfante. 2014. Detection of a novel intracellular microbiome hosted in arbuscular mycorrhizal fungi. ISME Journal 8 (2):257-270.

Deveau, A., C. Brulé, B. Palin, D. Champmartin, P. Rubini, J. Garbaye, A. Sarniguet, and P. Frey-Klett. 2010. Role of fungal trehalose and bacterial thiamine in the improved survival and growth of the ectomycorrhizal fungus Laccaria bicolor S238N and the helper bacterium Pseudomonas fluorescens BBc6R8. Environmental Microbiology Reports 2 (4):560-568.

Deveau, A., H. Gross, E. Morin, T. Karpinets, S. Utturkar, S. Mehnaz, F. Martin, P. Frey-Klett, and J. Labbé. 2014. Genome sequence of the mycorrhizal helper bacterium Pseudomonas fluorescens BBc6R8. Genome Announcements 2 (1):e01152-13.

Ding, Y., D. G. Robinson, and L. W. Jiang. 2014. Unconventional protein secretion (UPS) pathways in plants. Current Opinion in Cell Biology 29:107-115.

Doebeli, M., and N. Knowlton. 1998. The evolution of interspecific mutualisms. Proceedings of the National Academy of Sciences of the United States of America 95 (15):8676-8680.

Eggimann, P., J. Garbino, and D. Pittet. 2003. Epidemiology of Candida species infections in critically ill non-immunosuppressed patients. Lancet Infectious Diseases 3 (11):685-702. 
Espuny Tomas, J. M., D. M. Simon-Pujol, F. Congregado, and G. Suarez Fernandez. 1982. Nature of antagonism of fungi by bacteria isolated from soils. Soil Biology \& Biochemistry 14 (6):557-560.

Frank, S. A. 1994. Kin selection and virulence in the evolution of protocells and parasites. Proceedings of the Royal Society of London Series B-Biological Sciences 258 (1352):153-161.

Frank, S. A. 1996. Host-symbiont conflict over the mixing of symbiotic lineages. Proceedings of the Royal Society of London Series B-Biological Sciences 263 (1368):339-344.

Frank, S. A. 1996. Models of parasite virulence. Quarterly Review of Biology 71 (1):37-78.

Frey-Klett, P., P. Burlinson, A. Deveau, M. Barret, M. Tarkka, and A. Sarniguet. 2011. Bacterial-fungal interactions: hyphens between agricultural, clinical, environmental, and food microbiologists. Microbiology and Molecular Biology Reviews 75 (4):583-609.

Fujimura, R., A. Nishimura, S. Ohshima, Y. Sato, T. Nishizawa, K. Oshima, M. Hattori, K. Narisawa, and H. Ohta. 2014. Draft genome sequence of the betaproteobacterial endosymbiont associated with the fungus Mortierella elongata FMR23-6. Genome Announcements 2 (6):e01272-14.

Furuno, S., K. Pazolt, C. Rabe, T. R. Neu, H. Harms, and L. Y. Wick. 2010. Fungal mycelia allow chemotactic dispersal of polycyclic aromatic hydrocarbon-degrading bacteria in water-unsaturated systems. Environmental Microbiology 12 (6):1391-1398.

Ganz, T. 2009. Iron in innate immunity: starve the invaders. Current Opinion in Immunology 21 (1):63-67.

Garbaye, J. 1994. Helper bacteria: a new dimension to the mycorrhizal symbiosis. New Phytologist 128:197-210. 
961

962

Ghignone, S., A. Salvioli, I. Anca, E. Lumini, G. Ortu, L. Petiti, S. Cruveiller, V. Bianciotto, P. Piffanelli, L. Lanfranco, and P. Bonfante. 2012. The genome of the obligate endobacterium of an AM fungus reveals an interphylum network of nutritional interactions. ISME Journal 6 (1):136-145.

Gibson, J., A. Sood, and D. A. Hogan. 2009. Pseudomonas aeruginosa-Candida albicans interactions: localization and fungal toxicity of a phenazine derivative. Applied and Environmental Microbiology 75 (2):504-513.

Gkarmiri, K., R. D. Finlay, S. Alström, E. Thomas, M. A. Cubeta, and N. Högberg. 2015. Transcriptomic changes in the plant pathogenic fungus Rhizoctonia solani AG-3 in response to the antagonistic bacteria Serratia proteamaculans and Serratia plymuthica. BMC Genomics 16:630.

Gomulkiewicz, R., D. M. Drown, M. F. Dybdahl, W. Godsoe, S. L. Nuismer, K. M. Pepin, B. J. Ridenhour, C. I. Smith, and J. B. Yoder. 2007. Dos and don'ts of testing the geographic mosaic theory of coevolution. Heredity 98 (5):249-258.

Griffin, E. A. 2012. A first look at communication theory. 8th ed. ed. New York: McGraw-Hill.

Grube, M., and G. Berg. 2009. Microbial consortia of bacteria and fungi with focus on the lichen symbiosis. Fungal Biology Reviews 23 (3):72-85.

Gupta, N., A. Haque, G. Mukhopadhyay, R. P. Narayan, and R. Prasad. 2005. Interactions between bacteria and Candida in the burn wound. Burns 31 (3):375-8.

Hall, R. A., K. J. Turner, J. Chaloupka, F. Cottier, L. De Sordi, D. Sanglard, L. R. Levin, J. Buck, and F. A. Mühlschlegel. 2011. The quorum-sensing molecules farnesol/homoserine lactone and dodecanol operate via distinct modes of action in Candida albicans. Eukaryotic Cell 10 (8):1034-42. 
Hartmann, A., M. Schmid, D. van Tuinen, and G. Berg. 2009. Plant-driven selection of microbes. Plant and Soil 321 (1-2):235-257.

Herre, E. A., N. Knowlton, U. G. Mueller, and S. A. Rehner. 1999. The evolution of mutualisms: exploring the paths between conflict and cooperation. Trends in Ecology \& Evolution 14 (2):49-53.

Hoffman, M. T., and A. E. Arnold. 2010. Diverse bacteria inhabit living hyphae of phylogenetically diverse fungal endophytes. Applied and Environmental Microbiology 76 (12):4063-4075.

Hogan, D. A., and R. Kolter. 2002. Pseudomonas-Candida interactions: An ecological role for virulence factors. Science 296 (5576):2229-2232.

Hogan, D. A., Å. Vik, and R. Kolter. 2004. A Pseudomonas aeruginosa quorum-sensing molecule influences Candida albicans morphology. Molecular Microbiology 54 (5):1212-1223.

Hom, E. F., and A. W. Murray. 2014. Plant-fungal ecology. Niche engineering demonstrates a latent capacity for fungal-algal mutualism. Science 345 (6192):94-8.

Hoppe, B., T. Kahl, P. Karasch, T. Wubet, J. Bauhus, F. Buscot, and D. Kruger. 2014. Network analysis reveals ecological links between $\mathrm{N}$-gixing bacteria and wood-decaying fungi. Plos One 9 (2):e88141.

Hornby, J. M., E. C. Jensen, A. D. Lisec, J. J. Tasto, B. Jahnke, R. Shoemaker, P. Dussault, and K. W. Nickerson. 2001. Quorum sensing in the dimorphic fungus Candida albicans is mediated by farnesol. Applied and Environmental Microbiology 67 (7):2982-92.

Hsueh, Y. P., P. Mahanti, F. C. Schroeder, and P. W. Sternberg. 2013. Nematode-trapping fungi eavesdrop on nematode pheromones. Current Biology 23 (1):83-86. 
Huang, X.-F., J. M. Chaparro, K. F. Reardon, R. Zhang, Q. Shen, and J. M. Vivanco. 2014. Rhizosphere interactions: root exudates, microbes, and microbial communities. Botany 92:267-275.

Hughes, W., and H. Kim. 1973. Mycoflora in cystic fibrosis: Some ecologic aspects of Pseudomonas aeruginosa and Candida albicans. Mycopathologia et Mycologia Applicata 50 (3):261-269.

Ipcho, S., T. Sundelin, G. Erbs, H. C. Kistler, M.-A. Newman, and S. Olsson. 2016. Fungal innate immunity induced by bacterial Microbe-Associated Molecular Patterns (MAMPs). Submitted.

Jansa, J., P. Bukovská, and M. Gryndler. 2013. Mycorrhizal hyphae as ecological niche for highly specialized hypersymbionts - or just soil free-riders? Frontiers in Plant Science $4: 134$.

Janzen, D. H. 1985. On ecological fitting. Oikos 45 (3):308-310.

1010 Jargeat, P., C. Cosseau, B. Ola'h, A. Jauneau, P. Bonfante, J. Batut, and G. Bécard. 2004.

1011 Isolation, free-living capacities, and genome structure of "Candidatus Glomeribacter

1012 gigasporarum," the endocellular bacterium of the mycorrhizal fungus Gigaspora

1013 margarita. Journal of Bacteriology 186 (20):6876-6884.

1014 Jochum, C. C., L. E. Osborne, and G. Y. Yuen. 2006. Fusarium head blight biological control

1015 with Lysobacter enzymogenes. Biological Control 39 (3):336-344.

1016 Kai-Larsen, Y., G. H. Gudmundsson, and B. Agerberth. 2014. A review of the innate immune 1017 defence of the human foetus and newborn, with the emphasis on antimicrobial peptides. 1018 Acta Paediatrica 103 (10):1000-1008. 
1019 Kang, Y., I. McMillan, M. H. Norris, and T. T. Hoang. 2015. Single prokaryotic cell isolation 1020 and total transcript amplification protocol for transcriptomic analysis. Nature Protocols $1021 \quad 10(7): 974-84$.

1022 Kelsic, E. D., J. Zhao, K. Vetsigian, and R. Kishony. 2015. Counteraction of antibiotic 1023 production and degradation stabilizes microbial communities. Nature 521 (7553):516.

1024 Kerr, J. 1994. Inhibition of fungal growth by Pseudomonas aeruginosa and Pseudomonas 1025 cepacia isolated from patients with cystic fibrosis. The Journal of Infection 28 (3):305102610.

1027 Kerr, J. R. 1999. Bacterial inhibition of fungal growth and pathogenicity. Microbial Ecology in 1028 Health and Disease 11 (3):129-142.

1029 Kiers, E. T., M. Duhamel, Y. Beesetty, J. A. Mensah, O. Franken, E. Verbruggen, C. R. 1030 Fellbaum, G. A. Kowalchuk, M. M. Hart, A. Bago, T. M. Palmer, S. A. West, P. 1031 Vandenkoornhuyse, J. Jansa, and H. Bucking. 2011. Reciprocal rewards stabilize 1032 cooperation in the mycorrhizal symbiosis. Science 333 (6044):880-882.

1033 Kobayashi, D. Y., and J. A. Crouch. 2009. Bacterial/fungal interactions: From pathogens to 1034 mutualistic endosymbionts. Annual Review of Phytopathology 47:63-82.

1035 Kohlmeier, S., T. H. M. Smits, R. M. Ford, C. Keel, H. Harms, and L. Y. Wick. 2005. Taking the 1036 fungal highway: Mobilization of pollutant-degrading bacteria by fungi. Environmental 1037 Science \& Technology 39 (12):4640-4646.

1038 Kulp, A., and M. J. Kuehn. 2010. Biological functions and biogenesis of secreted bacterial outer 1039 membrane vesicles. Annual Review of Microbiology 64:163-184. 
1040

1041

1042

1043

1044

1045

1046

1047

1048

1049

1050

1051

1052

1053

1054

1055

1056

1057

1058

1059

1060

1061

Labbé, J. L., D. J. Weston, N. Dunkirk, D. A. Pelletier, and G. A. Tuskan. 2014. Newly identified helper bacteria stimulate ectomycorrhizal formation in Populus. Frontiers in Plant Science 5:579.

Lackner, G., and C. Hertweck. 2011. Impact of endofungal bacteria on infection biology, food safety, and drug development. PLoS Pathogens 7 (6):e1002096.

Lackner, G., N. Moebius, and C. Hertweck. 2011. Endofungal bacterium controls its host by an hrp type III secretion system. ISME Journal 5 (2):252-261.

Lackner, G., L. P. Partida-Martinez, and C. Hertweck. 2009. Endofungal bacteria as producers of mycotoxins. Trends in Microbiology 17 (12):570-576.

Lemanceau, P., D. Expert, F. Gaymard, P. A. H. M. Bakker, and J. F. Briat. 2009. Role of iron in plant-microbe interactions. Advances in Botanical Research 51:491-549.

Leone, M. R., G. Lackner, A. Silipo, R. Lanzetta, A. Molinaro, and C. Hertweck. 2010. An unusual galactofuranose lipopolysaccharide that ensures the intracellular survival of toxin-producing bacteria in their fungal host. Angewandte Chemie 49 (41):7476-7480.

Leveau, J. H. J., and G. M. Preston. 2008. Bacterial mycophagy: definition and diagnosis of a unique bacterial-fungal interaction. New Phytologist 177 (4):859-876.

Lewis, D. H. 1985. Symbiosis and mutualism: crisp concepts and soggy semantics. In The Biology of Mutualism. Ecology and Evolution., edited by D. H. Boucher. New York: Oxford University Press.

Li, S., L. Du, G. Yuen, and S. D. Harris. 2006. Distinct ceramide synthases regulate polarized growth in the filamentous fungus Aspergillus nidulans. Molecular Biology of the Cell 17 (3):1218-1227. 
1062

1063

1064

1065

1066

1067

1068

1069

1070

1071

1072

1073

1074

1075

1076

1077

1078

1079

1080

1081

1082

1083

Li, X., C. S. Quan, H. Y. Yu, and S. D. Fan. 2008. Multiple effects of a novel compound from Burkholderia cepacia against Candida albicans. FEMS Microbiology Letters 285

(2):250-6.

Lindsay, A. K., A. Deveau, A. E. Piispanen, and D. A. Hogan. 2012. Farnesol and cyclic AMP signaling effects on the hypha-to-yeast transition in Candida albicans. Eukaryotic Cell 11 (10):1219-25.

Lister, P. D., D. J. Wolter, and N. D. Hanson. 2009. Antibacterial-resistant Pseudomonas aeruginosa: Clinical impact and complex regulation of chromosomally encoded resistance mechanisms. Clinical Microbiology Reviews 22 (4):582-610.

Lopez-Medina, E., D. Fan, L. A. Coughlin, E. X. Ho, I. L. Lamont, C. Reimmann, L. V. Hooper, and A. Y. Koh. 2015. Candida albicans inhibits Pseudomonas aeruginosa virulence through suppression of pyochelin and pyoverdine biosynthesis. PLoS Pathogens 11 (8):e1005129.

Lott, T. J., R. E. Fundyga, R. J. Kuykendall, and J. Arnold. 2005. The human commensal yeast, Candida albicans, has an ancient origin. Fungal Genetics and Biology 42 (5):444-451.

Lumini, E., V. Bianciotto, P. Jargeat, M. Novero, A. Salvioli, A. Faccio, G. Bécard, and P. Bonfante. 2007. Presymbiotic growth and sporal morphology are affected in the arbuscular mycorrhizal fungus Gigaspora margarita cured of its endobacteria. Cellular Microbiology 9 (7):1716-1729.

Lyons, J. I., S. Y. Newell, R. P. Brown, and M. A. Moran. 2005. Screening for bacterial-fungal associations in a south-eastern US salt marsh using pre-established fungal monocultures. FEMS Microbiology Ecology 54 (2):179-187. 
Markel, T. A., P. R. Crisostomo, M. Wang, C. M. Herring, K. K. Meldrum, K. D. Lillemoe, and D. R. Meldrum. 2007. The struggle for iron: gastrointestinal microbes modulate the host immune response during infection. Journal of Leukocyte Biology 81 (2):393-400.

Martin, B. D., and E. Schwab. 2012. Current usage of symbiosis and associated terminology. International Journal of Biology 5 (1):32-45.

Mathioni, S. M., N. Patel, B. Riddick, J. A. Sweigard, K. J. Czymmek, J. L. Caplan, S. G. Kunjeti, S. Kunjeti, V. Raman, B. I. Hillman, D. Y. Kobayashi, and N. M. Donofrio. 2013. Transcriptomics of the rice blast fungus Magnaporthe oryzae in response to the

McCutcheon, J. P., and N. A. Moran. 2012. Extreme genome reduction in symbiotic bacteria. Nature Reviews Microbiology 10 (1):13-26.

McCutcheon, J. P., and C. D. von Dohlen. 2011. An interdependent metabolic patchwork in the nested symbiosis of mealybugs. Current Biology 21 (16):1366-72.

1098 McFrederick, Q. S., W. T. Wcislo, D. R. Taylor, H. D. Ishak, S. E. Dowd, and U. G. Mueller.

1099 2012. Environment or kin: whence do bees obtain acidophilic bacteria? Molecular

$1100 \quad$ Ecology $21(7): 1754-1768$.

1101

McManus, B. A., and D. C. Coleman. 2014. Molecular epidemiology, phylogeny and evolution

1103 Mela, F., K. Fritsche, W. de Boer, J. A. van Veen, L. H. de Graaff, M. van den Berg, and J. H. J.

1104 Leveau. 2011. Dual transcriptional profiling of a bacterial/fungal confrontation:

1105 Collimonas fungivorans versus Aspergillus niger. ISME Journal 5 (9):1494-1504. 
Mello, A., G. C. Ding, Y. M. Piceno, C. Napoli, L. M. Tom, T. Z. DeSantis, G. L. Andersen, K. Smalla, and P. Bonfante. 2013. Truffle brûlés have an impact on the diversity of soil bacterial communities. PLoS One 8 (4):e61945.

Michelsen, C. F., J. Watrous, M. A. Glaring, R. Kersten, N. Koyama, P. C. Dorrestein, and P. Stougaard. 2015. Nonribosomal peptides, key biocontrol components for Pseudomonas fluorescens In5, isolated from a Greenlandic suppressive soil. mBio 6 (2):e00079-15.

Moebius, N., Z. Üzüm, J. Dijksterhuis, G. Lackner, and C. Hertweck. 2014. Active invasion of bacteria into living fungal cells. eLife 3:e03007.

Mondo, S. J., K. H. Toomer, J. B. Morton, Y. Lekberg, and T. E. Pawlowska. 2012. Evolutionary stability in a 400-million-year-old heritable facultative mutualism. Evolution 66 (8):25642576.

Moran, N. A., J. P. McCutcheon, and A. Nakabachi. 2008. Genomics and evolution of heritable bacterial symbionts. Annual Review of Genetics 42:165-190.

Moretti, M., A. Grunau, D. Minerdi, P. Gehrig, B. Roschitzki, L. Eberl, A. Garibaldi, M. L. Gullino, and K. Riedel. 2010. A proteomics approach to study synergistic and antagonistic interactions of the fungal-bacterial consortium Fusarium oxysporum wildtype MSA 35. Proteomics 10 (18):3292-3320.

Moretti, M., D. Minerdi, P. Gehrig, A. Garibaldi, M. L. Gullino, and K. Riedel. 2012. A bacterial-fungal metaproteomic analysis enlightens an intriguing multicomponent interaction in the rhizosphere of Lactuca sativa. Journal of Proteome Research 11 (4):2061-2077.

Naito, M., J. B. Morton, and T. E. Pawlowska. 2015. Minimal genomes of mycoplasma-related endobacteria are plastic and contain host-derived genes for sustained life within 

of America 112 (25):7791-7796.

1131 Naito, M., and T. E. Pawlowska. 2016. The role of mobile genetic elements in evolutionary 1132 longevity of heritable endobacteria. Mobile Genetic Elements 6 (1):e1136375.

1133 Napoli, C., A. Mello, A. Borra, A. Vizzini, P. Sourzat, and P. Bonfante. 2010. Tuber

1134 melanosporum, when dominant, affects fungal dynamics in truffle grounds. New

$1135 \quad$ Phytologist 185 (1):237-247.

1136 Naumann, M., A. Schüßler, and P. Bonfante. 2010. The obligate endobacteria of arbuscular 1137 mycorrhizal fungi are ancient heritable components related to the Mollicutes. ISME

$1138 \quad$ Journal 4 (7):862-871.

1139 Nazir, R., D. I. Tazetdinova, and J. D. van Elsas. 2014. Burkholderia terrae BS001 migrates

1140 proficiently with diverse fungal hosts through soil and provides protection from $1141 \quad$ antifungal agents. Frontiers in Microbiology 5:598.

1142 Nazir, R., J. A. Warmink, H. Boersma, and J. D. van Elsas. 2010. Mechanisms that promote 1143 bacterial fitness in fungal-affected soil microhabitats. FEMS Microbiology Ecology 71 $1144 \quad(2): 169-185$.

1145 Nazir, R., J. A. Warmink, D. C. Voordes, H. H. van de Bovenkamp, and J. D. van Elsas. 2013. 1146 Inhibition of mushroom formation and induction of glycerol release - Ecological 1147 strategies of Burkholderia terrae BS001 to create a hospitable niche at the fungus $1148 \quad$ Lyophyllum sp. strain Karsten. Microbial Ecology 65 (1):245-254.

1149 Neupane, S., R. D. Finlay, S. Alström, M. Elfstrand, and N. Högberg. 2015. Transcriptional 1150 responses of the bacterial antagonist Serratia plymuthica to the fungal phytopathogen 1151 Rhizoctonia solani. Environmental Microbiology Reports 7 (1):123-127. 
1152

1153

1154

1155

1156

1157

1158

1159

1160

1161

1162

1163

1164

1165

1166

1167

1168

1169

1170

1171

1172

1173

1174

Nicolás, F. E., and R. M. Ruiz-Vázquez. 2013. Functional diversity of RNAi-associated sRNAs in fungi. International Journal of Molecular Sciences 14 (8):15348-15360.

Noë, R., and P. Hammerstein. 1994. Biological markets: supply and demand determine the effect of partner choice in cooperation, mutualism and mating. Behavioral Ecology and Sociobiology 35 (1):1-11.

Nürnberger, T., F. Brunner, B. Kemmerling, and L. Piater. 2004. Innate immunity in plants and animals: striking similarities and obvious differences. Immunological Reviews 198:249266.

Öhman, T., L. Teirilä, A.-M. Lahesmaa-Korpinen, W. Cypryk, V. Veckman, S. Saijo, H. Wolff, S. Hautaniemi, T. A. Nyman, and S. Matikainen. 2014. Dectin-1 pathway activates robust autophagy-dependent unconventional protein secretion in human macrophages. Journal of Immunology 192 (12):5952-5962.

Ong, S. T., J. Z. S. Ho, B. Ho, and J. L. Ding. 2006. Iron-withholding strategy in innate immunity. Immunobiology 211 (4):295-314.

Oozeer, R., K. van Limpt, T. Ludwig, K. Ben Amor, R. Martin, R. D. Wind, G. Boehm, and J. Knol. 2013. Intestinal microbiology in early life: specific prebiotics can have similar functionalities as human-milk oligosaccharides. American Journal of Clinical Nutrition 98 (2):561S-571S.

Page, R. D. M. 2003. Tangled Trees: Phylogeny, Cospeciation, and Coevolution. Chicago: The University of Chicago Press.

Palaniyandi, S. A., S. H. Yang, L. X. Zhang, and J. W. Suh. 2013. Effects of actinobacteria on plant disease suppression and growth promotion. Applied Microbiology and Biotechnology 97 (22):9621-9636. 
1175 Paoletti, M., and S. J. Saupe. 2009. Fungal incompatibility: Evolutionary origin in pathogen

1176 defense? Bioessays 31 (11):1201-1210.

1177 Paoletti, M., S. J. Saupe, and C. Clavé. 2007. Genesis of a fungal non-self recognition repertoire.

$1178 \quad$ Plos One 2 (3):e283.

1179 Partida-Martinez, L. P., and C. Hertweck. 2005. Pathogenic fungus harbours endosymbiotic

$1180 \quad$ bacteria for toxin production. Nature 437 (7060):884-888.

1181 Partida-Martinez, L. P., S. Monajembashi, K. O. Greulich, and C. Hertweck. 2007.

1182 Endosymbiont-dependent host reproduction maintains bacterial-fungal mutualism.

$1183 \quad$ Current Biology 17 (9):773-777.

1184 Pawlowska, A. M., E. Zannini, A. Coffey, and E. K. Arendt. 2012. "Green preservatives":

1185 Combating fungi in the food and feed industry by applying antifungal lactic acid bacteria.

1186 In Advances in Food and Nutrition Research, edited by J. Henry: Elsevier Inc.

1187 Peleg, A. Y., D. A. Hogan, and E. Mylonakis. 2010. Medically important bacterial-fungal

1188 interactions. Nature Reviews Microbiology 8 (5):340-349.

1189 Perotto, S., and P. Bonfante. 1997. Bacterial associations with mycorrhizal fungi: Close and

1190 distant friends in the rhizosphere. Trends in Microbiology 5 (12):496-501.

1191 Piispanen, A. E., and D. A. Hogan. 2008. PEPped up: Induction of Candida albicans virulence

1192 by bacterial cell wall fragments. Cell Host \& Microbe 4 (1):1-2.

1193 Pion, M., J. E. Spangenberg, A. Simon, S. Bindschedler, C. Flury, A. Chatelain, R. Bshary, D.

1194 Job, and P. Junier. 2013. Bacterial farming by the fungus Morchella crassipes.

1195 Proceedings of the Royal Society B-Biological Sciences 280 (1773):20132242. 
Pliego, C., C. Ramos, A. de Vicente, and F. M. Cazorla. 2011. Screening for candidate bacterial biocontrol agents against soilborne fungal plant pathogens. Plant and Soil 340 (1-2):505520.

Rajamäki, K., T. Nordström, K. Nurmi, K. E. O. Åkerman, P. T. Kovanen, K. Öörni, and K. K. Eklund. 2013. Extracellular acidosis is a novel danger signal alerting innate immunity via the NLRP3 inflammasome. Journal of Biological Chemistry 288 (19):13410-13419.

Ramírez-Puebla, S. T., L. E. Servín-Garcidueñas, B. Jiménez-Marín, L. M. Bolaños, M. Rosenblueth, J. Martínez, M. Antonio Rogel, E. Ormeño-Orrillo, and E. MartínezRomero. 2013. Gut and root microbiota commonalities. Applied and Environmental Microbiology 79 (1):2-9.

Remis, J. P., D. Wei, A. Gorur, M. Zemla, J. Haraga, S. Allen, H. E. Witkowska, J. W. Costerton, J. E. Berleman, and M. Auer. 2014. Bacterial social networks: structure and composition of Myxococcus xanthus outer membrane vesicle chains. Environmental Microbiology 16 (2):598-610.

Rodrigues, M. L., E. S. Nakayasu, I. C. Almeida, and L. Nimrichter. 2014. The impact of proteomics on the understanding of functions and biogenesis of fungal extracellular vesicles. Journal of Proteomics 97:177-186.

Ruiz-Herrera, J., C. León-Ramírez, A. Vera-Nuñez, A. Sánchez-Arreguín, R. Ruiz-Medrano, H. Salgado-Lugo, L. Sánchez-Segura, and J. J. Peña-Cabriales. 2015. A novel intracellular nitrogen-fixing symbiosis made by Ustilago maydis and Bacillus spp. New Phytologist $207(3): 769-777$.

Sachs, J. L., U. G. Mueller, T. P. Wilcox, and J. J. Bull. 2004. The evolution of cooperation. Quarterly Review of Biology 79 (2):135-160. 
Saliba, A. E., A. J. Westermann, S. A. Gorski, and J. Vogel. 2014. Single-cell RNA-seq: advances and future challenges. Nucleic Acids Research 42 (14):8845-8860.

Salvioli, A., S. Ghignone, M. Novero, L. Navazio, F. Venice, P. Bagnaresi, and P. Bonfante. 2016. Symbiosis with an endobacterium increases the fitness of a mycorrhizal fungus, raising its bioenergetic potential. ISME Journal 10 (1):130-144.

Samuel, M., M. Bleackley, M. Anderson, and S. Mathivanan. 2015. Extracellular vesicles including exosomes in cross kingdom regulation: a viewpoint from plant-fungal interactions. Frontiers in Plant Science 6:766.

Sato, Y., K. Narisawa, K. Tsuruta, M. Umezu, T. Nishizawa, K. Tanaka, K. Yamaguchi, M. Komatsuzaki, and H. Ohta. 2010. Detection of betaproteobacteria inside the mycelium of the fungus Mortierella elongata. Microbes and Environments 25 (4):321-324.

Scherlach, K., B. Busch, G. Lackner, U. Paszkowski, and C. Hertweck. 2012. Symbiotic cooperation in the biosynthesis of a phytotoxin. Angewandte Chemie 51 (38):9615-9618.

Scherlach, K., K. Graupner, and C. Hertweck. 2013. Molecular bacteria-fungi interactions: effects on environment, food, and medicine. Annual Review of Microbiology 67:375-97.

Scheublin, T. R., I. R. Sanders, C. Keel, and J. R. van der Meer. 2010. Characterisation of microbial communities colonising the hyphal surfaces of arbuscular mycorrhizal fungi. ISME Journal 4 (6):752-763.

Schmitt, I., L. P. Partida-Martinez, R. Winkler, K. Voigt, E. Einax, F. Dölz, S. Telle, J. Wöstemeyer, and C. Hertweck. 2008. Evolution of host resistance in a toxin-producing bacterial-fungal alliance. ISME Journal 2 (6):632-641. 
Scholtens, P. A. M. J., R. Oozeer, R. Martin, K. B. Amor, and J. Knol. 2012. The early settlers: Intestinal microbiology in early life. Annual Review of Food Science and Technology 3 (3):425-447.

Schroeckh, V., K. Scherlach, H.-W. Nützmann, E. Shelest, W. Schmidt-Heck, J. Schuemann, K. Martin, C. Hertweck, and A. A. Brakhage. 2009. Intimate bacterial-fungal interaction triggers biosynthesis of archetypal polyketides in Aspergillus nidulans. Proceedings of the National Academy of Sciences of the United States of America 106 (34):14558-14563.

Schüßler, A., D. Mollenhauer, E. Schnepf, and M. Kluge. 1994. Geosiphon pyriforme, an endosymbiotic association of fungus and cyanobacteria: the spore structure resembles that of arbuscular mycorrhizal (AM) fungi. Botanica Acta 107 (1):36-45.

Scully, C., M. el-Kabir, and L. P. Samaranayake. 1994. Candida and oral candidosis: A review. Critical Reviews in Oral Biology and Medicine 5 (2):125-157.

Selin, C., R. Habibian, N. Poritsanos, S. N. P. Athukorala, D. Fernando, and T. R. de Kievit. 2010. Phenazines are not essential for Pseudomonas chlororaphis PA23 biocontrol of Sclerotinia sclerotiorum, but do play a role in biofilm formation. FEMS Microbiology Ecology 71 (1):73-83.

Seneviratne, G., and H. S. Jayasinghearachchi. 2003. Mycelial colonization by bradyrhizobia and azorhizobia. Journal of Biosciences 28 (2):243-247.

Seneviratne, G., J. S. Zavahir, W. M. M. S. Bandara, and M. L. M. A. W. Weerasekara. 2008. Fungal-bacterial biofilms: their development for novel biotechnological applications. World Journal of Microbiology \& Biotechnology 24 (6):739-743.

Sengupta, S., M. K. Chattopadhyay, and H.-P. Grossart. 2013. The multifaceted roles of antibiotics and antibiotic resistance in nature. Frontiers in Microbiology 4:47. 
Sharma, M., M. Schmid, M. Rothballer, G. Hause, A. Zuccaro, J. Imani, P. Kämpfer, E. Domann, P. Schäfer, A. Hartmann, and K. H. Kogel. 2008. Detection and identification of bacteria intimately associated with fungi of the order Sebacinales. Cellular Microbiology 10 (11):2235-2246.

Siavoshi, F., and P. Saniee. 2014. Vacuoles of Candida yeast as a specialized niche for Helicobacter pylori. World Journal of Gastroenterology 20 (18):5263-73.

Simon, A., S. Bindschedler, D. Job, L. Y. Wick, S. Filippidou, W. M. Kooli, E. P. Verrecchia, and P. Junier. 2015. Exploiting the fungal highway: development of a novel tool for the in situ isolation of bacteria migrating along fungal mycelium. FEMS Microbiology Ecology 91 (11):10.1093/femsec/ v116.

Smith, S. E., and D. J. Read. 2008. Mycorrhizal Symbiosis. Third ed. New York: Academic Press.

Splivallo, R., A. Deveau, N. Valdez, N. Kirchhoff, P. Frey-Klett, and P. Karlovsky. 2015. Bacteria associated with truffle-fruiting bodies contribute to truffle aroma. Environmental Microbiology 17 (8):2647-60.

Splivallo, R., S. Ottonello, A. Mello, and P. Karlovsky. 2011. Truffle volatiles: from chemical ecology to aroma biosynthesis. New Phytologist 189 (3):688-99.

Staněk, M. 1984. Microorganisms in the hyphosphere of fungi. I. Introduction. Česká Mykologie $38(1): 1-10$.

Suárez-Moreno, Z. R., J. Caballero-Mellado, B. G. Coutinho, L. Mendonça-Previato, E. K. James, and V. Venturi. 2012. Common features of environmental and potentially beneficial plant-associated Burkholderia. Microbial Ecology 63 (2):249-266. 
Susi, P., G. Aktuganov, J. Himanen, and T. Korpela. 2011. Biological control of wood decay against fungal infection. Journal of Environmental Management 92 (7):1681-1689.

Teichert, I., G. Wolff, U. Kück, and M. Nowrousian. 2012. Combining laser microdissection and RNA-seq to chart the transcriptional landscape of fungal development. BMC Genomics $13: 511$.

Thompson, J. N. 2005. The Geographic Mosaic of Coevolution. Chicago: University of Chicago Press.

Thompson, J. N. 2014. Interaction and Coevolution. Chicago: University of Chicago Press.

Thrane, C., T. H. Nielsen, M. N. Nielsen, J. Sørensen, and S. Olsson. 2000. Viscosinamideproducing Pseudomonas fluorescens DR54 exerts a biocontrol effect on Pythium ultimum in sugar beet rhizosphere. FEMS Microbiology Ecology 33 (2):139-146.

Tisserant, E., M. Malbreil, A. Kuo, A. Kohler, A. Symeonidi, R. Balestrini, P. Charron, N. Duensing, N. Frei dit Frey, V. Gianinazzi-Pearson, L. B. Gilbert, Y. Handa, J. R. Herr, M. Hijri, R. Koul, M. Kawaguchi, F. Krajinski, P. J. Lammers, F. G. Masclaux, C. Murat, E. Morin, S. Ndikumana, M. Pagni, D. Petitpierre, N. Requena, P. Rosikiewicz, R. Riley, K. Saito, H. San Clemente, H. Shapiro, D. van Tuinen, G. Bécard, P. Bonfante, U. Paszkowski, Y. Y. Shachar-Hill, G. A. Tuskan, P. W. Young, I. R. Sanders, B. Henrissat, S. A. Rensing, I. V. Grigoriev, N. Corradi, C. Roux, and F. Martin. 2013. Genome of an arbuscular mycorrhizal fungus provides insight into the oldest plant symbiosis. Proceedings of the National Academy of Sciences of the United States of America 110 (50):20117-20122.

Toomer, K. H., X. Chen, M. Naito, S. J. Mondo, H. C. den Bakker, N. W. VanKuren, Y. Lekberg, J. B. Morton, and T. E. Pawlowska. 2015. Molecular evolution patterns reveal 
life history features of mycoplasma-related endobacteria associated with arbuscular mycorrhizal fungi. Molecular Ecology 24 (13):3485-3500.

1310 Tornberg, K., E. Bååth, and S. Olsson. 2003. Fungal growth and effects of different wood 1311 decomposing fungi on the indigenous bacterial community of polluted and unpolluted 1312 soils. Biology and Fertility of Soils 37 (3):190-197.

1313 Torres-Cortés, G., S. Ghignone, P. Bonfante, and A. Schüßler. 2015. Mosaic genome of

1314 endobacteria in arbuscular mycorrhizal fungi: Transkingdom gene transfer in an ancient

1315 mycoplasma-fungus association. Proceedings of the National Academy of Sciences of the

$1316 \quad$ United States of America 112 (25):7785-7790.

1317 Trinchieri, G. 2014. Cancer as a disease of the metaorganism. Immunology 143 (Suppl 2):13.

1318 Trivers, R. L. 1971. The evolution of reciprocal altruism. Quarterly Review of Biology 46:35-57.

1319 Uzum, Z., A. Silipo, G. Lackner, A. De Felice, A. Molinaro, and C. Hertweck. 2015. Structure, genetics and function of an exopolysaccharide produced by a bacterium living within fungal hyphae. ChemBioChem 16 (3):387-92.

Val, F., S. Desender, K. Bernard, P. Potin, G. Hamelin, and D. Andrivon. 2008. A culture filtrate of Phytophthora infestans primes defense reaction in potato cell suspensions.

1325 Vannini, C., A. Carpentieri, A. Salvioli, M. Novero, M. Marsoni, L. Testa, M. C. De Pinto, A. and O. A. Stepnaya. 2013. The role of membrane vesicles in secretion of Lysobacter sp 

2):142-151.

Verma, N., and B. C. Behera. 2015. In vitro culture of lichen partners: Need and implications. In Recent Advances in Lichenology: Modern Methods and Approaches in Biomonitoring and Bioprospection, edited by D. K. Upreti, P. K. Divakar, V. Shukla and R. Bajpai. New Dehli: Springer India.

Wang, X., G. H. Li, C. G. Zou, X. L. Ji, T. Liu, P. J. Zhao, L. M. Liang, J. P. Xu, Z. Q. An, X. Zheng, Y. K. Qin, M. Q. Tian, Y. Y. Xu, Y. C. Ma, Z. F. Yu, X. W. Huang, S. Q. Liu, X. M. Niu, J. K. Yang, Y. Huang, and K. Q. Zhang. 2014. Bacteria can mobilize nematodetrapping fungi to kill nematodes. Nature Communications 5:5776.

Warmink, J. A., R. Nazir, B. Corten, and J. D. van Elsas. 2011. Hitchhikers on the fungal highway: The helper effect for bacterial migration via fungal hyphae. Soil Biology \& Biochemistry 43 (4):760-765.

Warmink, J. A., R. Nazir, and J. D. van Elsas. 2009. Universal and species-specific bacterial 'fungiphiles' in the mycospheres of different basidiomycetous fungi. Environmental Microbiology 11 (2):300-12.

Watrous, J. D., T. Alexandrov, and P. C. Dorrestein. 2011. The evolving field of imaging mass spectrometry and its impact on future biological research. Journal of Mass Spectrometry 46 (2):209-222.

Weyl, E. G., M. E. Frederickson, D. W. Yu, and N. E. Pierce. 2010. Economic contract theory tests models of mutualism. Proceedings of the National Academy of Sciences of the United States of America 107 (36):15712-15716. 
Wick, L. Y., R. Remer, B. Wuerz, J. Reichenbach, S. Braun, F. Schaerfer, and H. Harms. 2007. Effect of fungal hyphae on the access of bacteria to phenanthrene in soil. Environmental Science \& Technology 41 (2):500-505.

Winsor, G. L., B. Khaira, T. Van Rossum, R. Lo, M. D. Whiteside, and F. S. Brinkman. 2008. The Burkholderia Genome Database: facilitating flexible queries and comparative analyses. Bioinformatics 24 (23):2803-4.

Xu, X. L., R. T. H. Lee, H. M. Fang, Y. M. Wang, R. Li, H. Zou, Y. Zhu, and Y. Wang. 2008. Bacterial peptidoglycan triggers Candida albicans hyphal growth by directly activating the adenylyl cyclase Cyr1p. Cell Host \& Microbe 4 (1):28-39.

Yamamura, N. 1993. Vertical transmission and evolution of mutualism from parasitism. Theoretical Population Biology 44 (1):95-109.

Yoshida, S., A. Ohba, Y.-M. Liang, M. Koitabashi, and S. Tsushima. 2012. Specificity of Pseudomonas isolates on healthy and Fusarium head blight-infected spikelets of wheat heads. Microbial Ecology 64 (1):214-225.

Young, D. B., I. Comas, and L. P. de Carvalho. 2015. Phylogenetic analysis of vitamin B12related metabolism in Mycobacterium tuberculosis. Frontiers in Molecular Biosciences $2: 6$

Yu, F., K. Zaleta-Rivera, X. Zhu, J. Huffman, J. C. Millet, S. D. Harris, G. Yuen, X.-C. Li, and L. Du. 2007. Structure and biosynthesis of heat-stable antifungal factor (HSAF), a broadspectrum antimycotic with a novel mode of action. Antimicrobial Agents and Chemotherapy 51 (1):64-72.

Zamioudis, C., and C. M. J. Pieterse. 2012. Modulation of host immunity by beneficial microbes. Molecular Plant-Microbe Interactions 25 (2):139-150. 
1376 Zhang, M., and R. Schekman. 2013. Unconventional secretion, unconventional solutions.

$1377 \quad$ Science $340(6132): 559-561$.

1378 
1380 Table 1. Mechanisms shared by diverse eukaryotic hosts to select beneficial organisms

1381 colonizing host surfaces involved in nutrient uptake.

\begin{tabular}{ll}
\hline General for eukaryotic hosts (means) & Host specific (means) \\
\hline $\begin{array}{l}\text { pH reduction by the host } \\
\text { (secretion of hydrogen ion) }\end{array}$ & $\begin{array}{l}\text { Secreted antibacterial compounds } \\
\text { (production and secretion of secondary } \\
\text { metabolites and/or antimicrobial peptides, } \\
\text { AMPs) }\end{array}$ \\
$\begin{array}{l}\text { Host reduction of iron availability } \\
\text { (activation of host iron uptake machinery) }\end{array}$ & $\begin{array}{l}\text { Provisioning of beneficial bacteria with } \\
\text { specific nutrients not common in other } \\
\text { environments. } \\
\text { (synthesis and secretion of specific carbon } \\
\text { sources) }\end{array}$ \\
\hline
\end{tabular}


1382

1383

1384 Figure 1. Metaorganisms comprise fungal hosts and their various bacterial symbionts.

1385

1386

1387

1388

1389

1390

1391

1392

\section{Figure Captions}

\section{Figure 2. Evolutionary theory predictions on the role of vertical transmission in the} evolution of mutualisms from antagonisms. Hosts are depicted as red ovals; host-positive symbionts are shown as green dots, host-negative symbionts as purple dots. Relative host fitness is reflected by the size of ovals.

\section{Figure 3. Hypothetical evolutionary trajectories in heritable mutualisms. Hosts are} depicted as red ovals; endosymbionts are shown as green dots. Relative host fitness is reflected by the size of ovals. (A) Evolutionary trajectory leading to obligate reciprocal partner dependence. (B) Shifting environmental conditions are expected to arrest an association at the facultative dependence stage. If conditions remain unfavorable for prolonged periods of time, host populations would be expected to completely lose endosymbionts. Modified from Mondo et al. (2012).

\section{Figure 4. Model of plant-fungus-endobacterium interaction (Courtesy of M. Novero).}

Genome-sequencing results for Candidatus Glomeribacter gigasporarum indicate that the bacterium fully depends on the fungal metabolism, including carbon $(\mathrm{C})$, phosphorus $(\mathrm{P})$, and nitrogen $(\mathrm{N})$ metabolism. In contrast, the fungus depends on its green plant host for $\mathrm{C}$ uptake only. 
1405 Figure 5. Evolutionary theory predictions linking the type of symbiosis with the intra-host

1406 relatedness of symbionts and symbiont transmission. Hosts are shown as red ovals. Relative

1407 host fitness is reflected by the size of ovals. Endosymbionts are represented by green and purple

1408 dots with different shades depicting different genotypes. Modified from Toomer et al. (2015). 
1409

1410 Figure 1

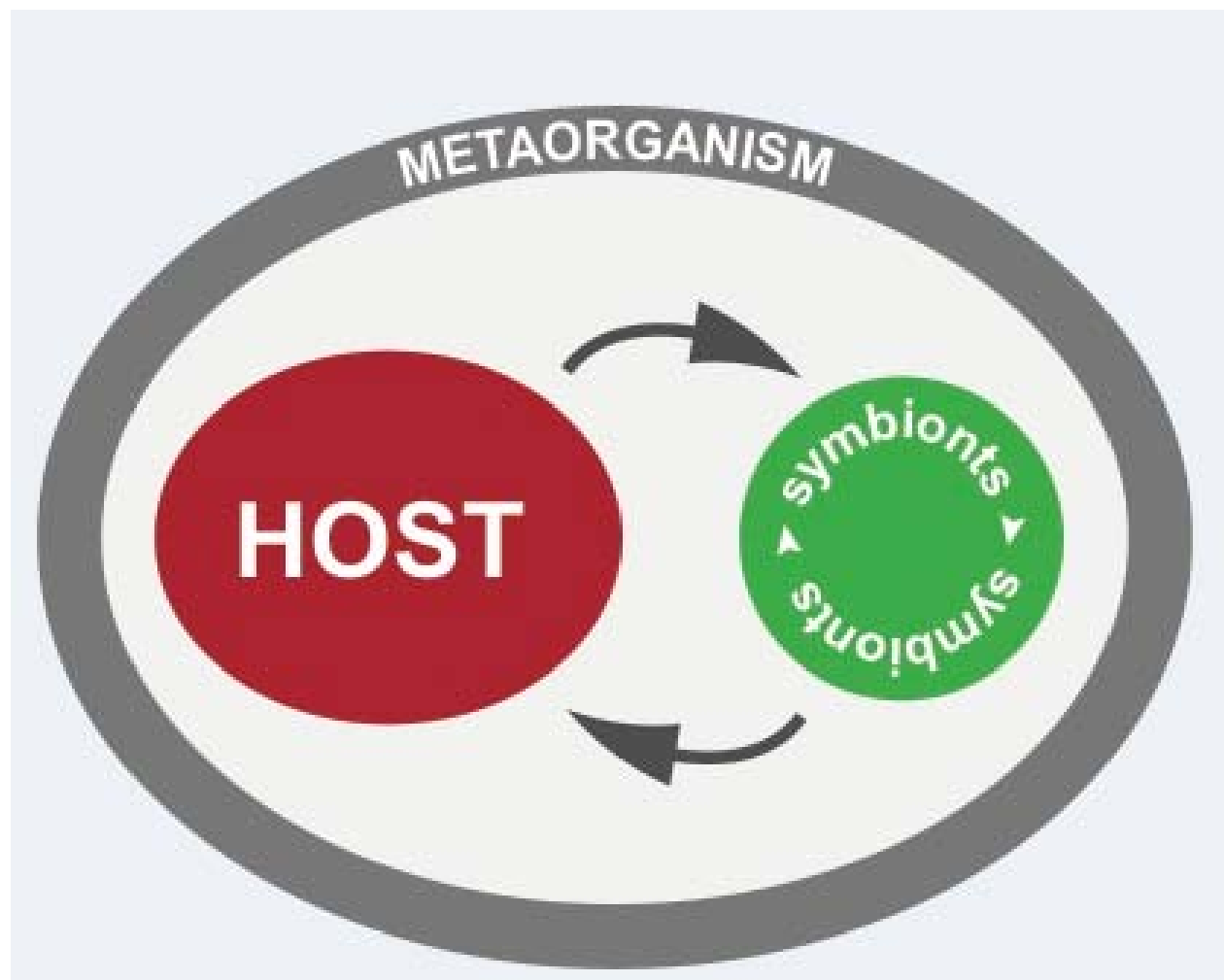

1411 
1412

1413 Figure 2

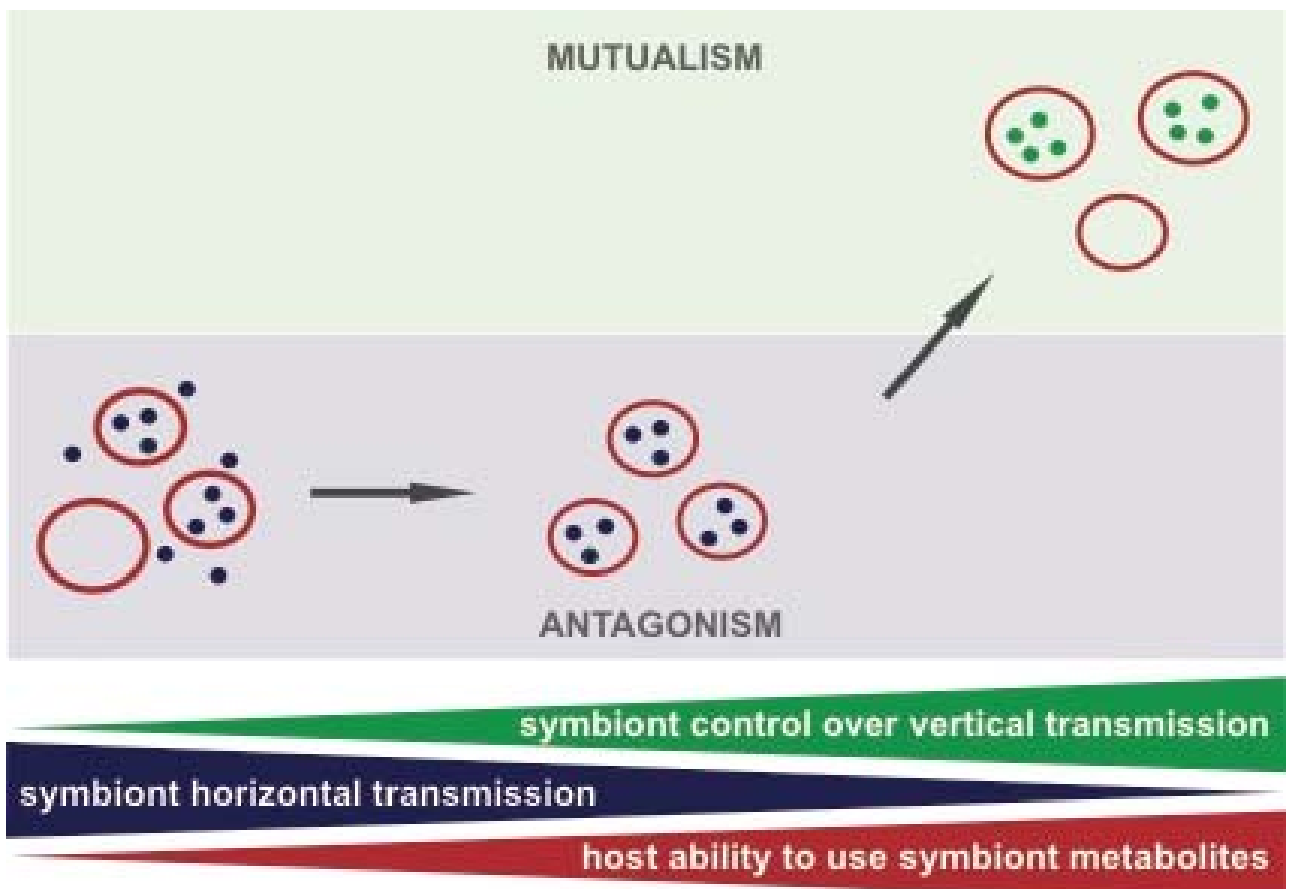

1414 
1415

1416 Figure 3
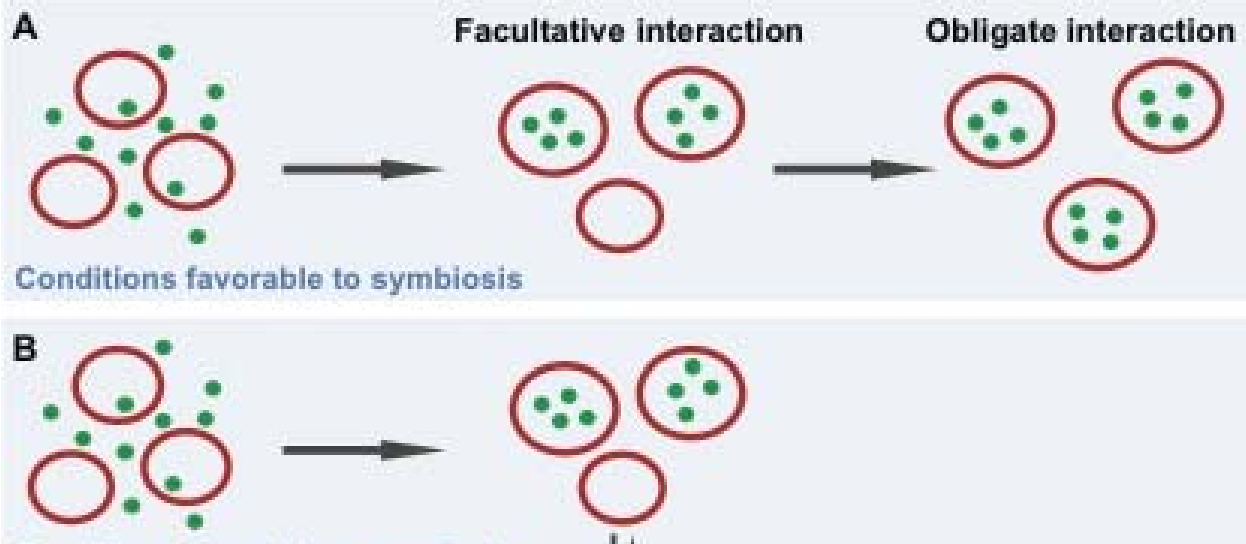

Conditions favorable to symbiosis

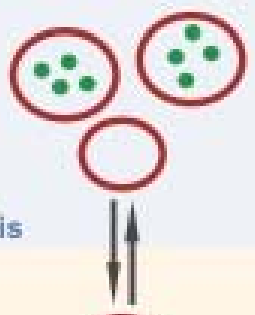

(2)

Conditions unfavorable to symbiosis

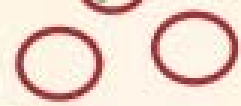

symbiont horizontal transmission

1417 
1418

$1419 \quad$ Figure 4

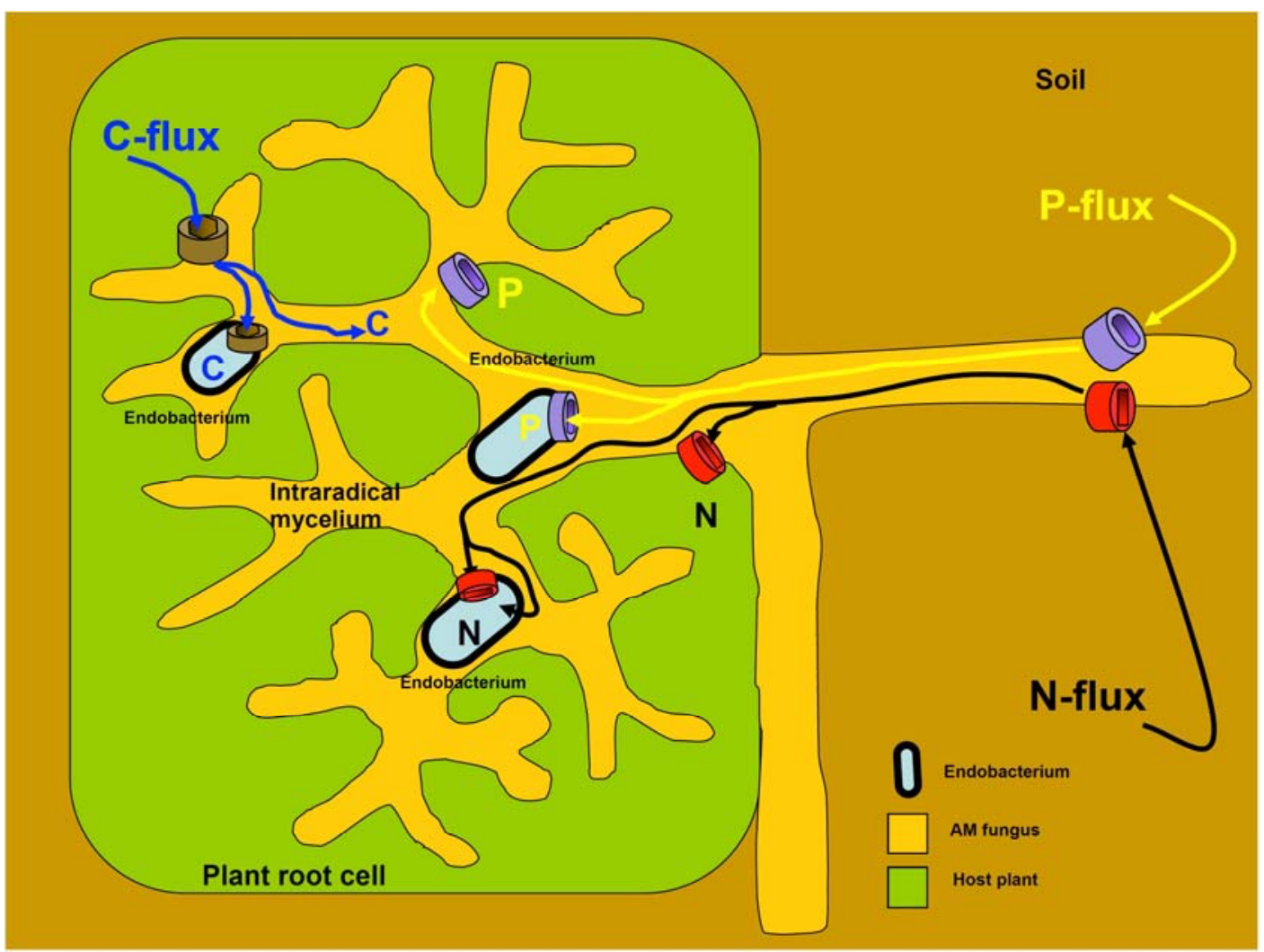

1420 
1421

1422 Figure 5
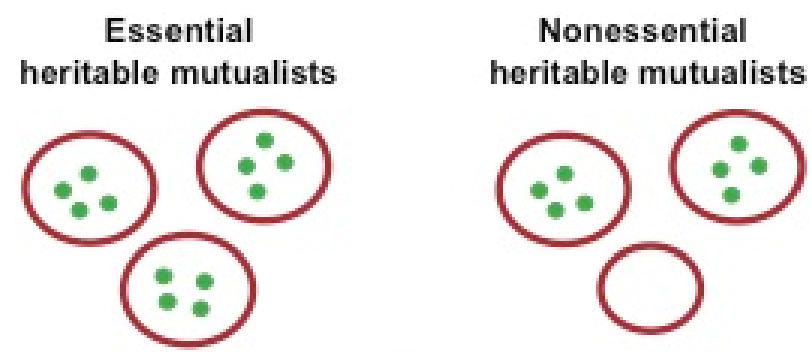

Heritable parasites

intra-host symbiont relatedness

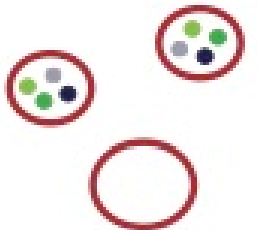

1423

symbiont horizontal transmission 